\title{
Identification, Characterization and Expression Analysis Reveal the Potential Function of Annexin Genes in Response to Abiotic stress, Calcium and Hormones in Cassava (Manihot esculeta Crantz)
}

\section{Ruimei Li}

Institute of Tropical Bioscience and Biotechnology, Chinese Acadamy of Tropical Agriculture Sciences https://orcid.org/0000-0003-3075-9512

Yuqing Wang

Hainan University

Yangjiao Zhou

Hainan University

Tingting Qiu

Hainan University

\section{Yu Song}

Institute of Germplasm Resources

Yuan Yao

Institute of Tropical Bioscience and Biotechnology

Jiao Liu

Institute of Tropical Bioscience and Biotechnology

Shaoping Fu

Institute of Tropical Bioscience and Biothechnology

Xinwen Hu

Hainan University

Yingdui He

Haikou Experimental Station, Chinese Academy of Triopical Agriculture Sciences

Jianchun Guo ( $\sim$ guojianchun@itbb.org.cn )

Research article

Keywords: cassava, annexin, expression patterns, abiotic stress

Posted Date: July 18th, 2019

DOl: https://doi.org/10.21203/rs.2.11537/v1 
License: (c) (i) This work is licensed under a Creative Commons Attribution 4.0 International License. Read Full License 


\section{Abstract}

Background The calcium (Ca2+)-dependent phospholipid binding protein annexin gene family, which is known to be related to membrane lipid and cytoskeletal components, is involved in a diverse range of biological functions. However, in cassava (Manihot esculenta Crantz), no studies focusing on the roles of annexin genes in response to abiotic stresses, calcium, and hormones have been informed. Results 12 annexin genes were found and assigned to eight chromosomes in the cassava genome. All of the MeAnns contain a typical annexin domain with four 70-amino acid repeats. The MeAnns are classified into six groups in the phylogenetic tree. In their promoter regions, MeAnns possess at least 3 hormone response-related cis-elements and 1 abiotic stress response-related cis-acting element. MeAnn1, MeAnn2 and MeAnn 5 exhibit very high levels of expression in each tested organs or tissues. By contrast, MeAnn12 exhibits very low levels in all the tested organs or tissues. qRT-PCR analysis indicates that both MeAnn5 and MeAnn9 have significantly high expression in leaves after cold, drought, and salt treatments and are highly responsive to $\mathrm{CaCl} 2, \mathrm{GA}$ and $\mathrm{JA}$ treatments. MeAnn2 and MeAnn10 are significantly downregulated in leaves by cold, drought and salt stress and negatively respond to $\mathrm{CaCl} 2, \mathrm{GA}$ and $\mathrm{JA}$. The expression patterns of MeAnns under cold, drought, and salt stress are irregular in shoots. In roots, MeAnn1 and MeAnn9 are downregulated by cold, $\mathrm{CaCl} 2$ and JA treatments, while their other gene expression patterns are irregular. Conclutions In this study, we identified annexin genes in cassava and our expression profiling analysis demonstrated that cassava annexin genes responded to multiple stresses. Our results laid the foundation for further study of the function of cassava anesxin genes and provided an entry point for understanding the response mechanism of cassava to abiotic stress.

\section{Background}

As an evolutionarily conserved group, annexins are calcium $\left(\mathrm{Ca}^{2+}\right)$-dependent phospholipid binding proteins known to be related to membrane lipid and cytoskeletal components [1,2]. The remarkable and special characteristics of these proteins function in membrane organization, vesicle trafficking and the $\mathrm{Ca}^{2+}$ signaling pathway and are involved in a diverse range of cellular functions [1]. Generally, annexins exist in almost all eukaryotes, among which plant annexins represent a monophyletic branch of homologs that evolved from green algae; however, some prokaryotes also have annexins [2]. Annexin multigene families have high diversity numbers across various organisms [3]. The primitive variety of annexin proteins date back to 1-1.5 billion years ago in Giardia lambia (unicellular protist) [4]. The annexin gene (Ann) was firstly detected in tomato over two decades ago [5], after which it has also been identified in Giardia lamblia [4], Capsicum annuum [6], Nicotiana tabacum [7], Triticum aestivum [8], Arabidopsis thaliana [9, 10], Brassica juncea [11] and Oryza sativa [12]. Among these, annexin genes in $A$. thaliana, $B$. juncea and $O$. sativa have been identified and well-characterized. So far, studies have shown that these plants have relatively large and diverse annexin families, whereas the original low single-cell plants, such as Micromonas and Ostreococcus, have small families [13, 14]. In vertebrates, low annexin A1 expression has been predicted to have a role in the induction of chemotherapy in oral cancer patients [15]. The annexin gene Ann2 in vertebrates is a multipotent calcium and anionic phospholipid-binding 
protein that is found to play a considerable role in endocytosis, exocytosis, ion channel conduction, membrane tissues and other processes [16]. During nodule formation in Medicago truncatula, annexins perform important functions in the generation and transmission of calcium signals [3]. A previous study has indicated that the GbAnn6 interacted with Actin 1 toregulating the fiber elongation in cotton [17]. AtAnn 1 from $A$. thaliana is significant for regulating $\mathrm{H}_{2} \mathrm{O}_{2}$-induced root calcium signaling [18].

Structurally, almost all annexins have four to eight repeats of a 60-70 amino acid motif [12]. It has been reported that annexins consist of four annexin motif repeats, with the conserved GxGT-(38 residues)-D/E calcium binding sequence exist in the first and fourth motif repeats [3]. Compared with vertebrates, annexins from plants have a short N-terminal region and lack calcium binding sites (CBS) in their second and third motif repeats [3]. Reports has also demonstrated the presence or absence of motifs that play key roles in calcium channels, peroxidases, and ATPase/GTPase activity [19]. From the phylogenetic point of view, plant annexins and animal annexins are independent populations $[3,19]$.

In recent studies, plant annexins have been reported to be expressed in many diverse tissues during plant development $[9,12]$. Tissue-specific expression profiles of plant annexin families have been observed in plants such as $A$. thaliana [9], triticum astivum [20], and 0 . sativa [12]. AtAnn 1 is expressed in all examined tissues, but is richest in stems, while AtAnn2 is most abundant in roots [9]. Additionally, many studies have reported the functions of annexins in response to abiotic stresses. Abiotic stresses start with stress perception and then lead to the activation of gene expression through signaling pathways, consequently influencing plant physiology, growth and development [21, 22]. It has been reported that some annexin genes related to membrane organization are involved in abiotic stress tolerance [20]. For instance, overexpression of AtAnn 1 from A. thaliana inplants enhanced drought tolerance, while AtAnn 1 knockout in plants reduced drought tolerance[10]. AtAnn1 and AtAnn4 from Arabidopsis can interact with one another and are adjusted to response to stresses such as aridity and salt [23]. Expression analysis also revealed differential annexin expression patterns in $O$. sativa seedling stages under diverse abiotic stresses such as salt, drought, cold and heat [12].

In the tropical and subtropical regions of the world, cassava (Manihot esculenta Crantz) is generally known as an essential food source for at least 500 million people [24, 25]. Recently, many studies have focused on increasing its productive yield and understanding the effects of abiotic stresses such drought and infertility [26]. In this present study, twelve MeAnn annexin genes from cassava have been identified. The conserved domains, motif distribution, evolutionary relationships, gene structures, and chromosomal localization of the MeAnn genes were inquired into. To identify the possible roles of MeAnns in cassava, the cis-elements on the MeAnn promoters were predicted. The differential expression of MeAnns under abiotic stresses, such as salt, cold and drought stresses, and during calcium ion and hormone signaling were examined by qRT-PCR in cassava. These results will help to ulteriorly reveal the important biological functions of MeAnn genes in cassava.

\section{Results}




\section{Genome-wide identification and characterization of MeAnns}

Using genome-wide retrieval techniques, in all, 12 supposed Annexin genes were found out in the cassava genome and named MeAnn1-12. ProtParam was used to characterize the MeAnn physiological and biochemical characteristics. The results showed that MeAnn lengths ranged from 309 (MeAnn12) to 382 (MeAnn6) AA (amino acids), with the predicted MW (molecular weights) ranging from 35.26 (MeAnn12) to 43.78 (MeAnn6) kDa. The GRAVY (grand average of hydropathicity) of the MeAnns ranged from -0.554 (MeAnn5) to -0.271 (MeAnn7), and the theoretical pl (isoelectric point) ranged from 5.80 (MeAnn6) to 9.46 (MeAnn9). The II (instability index) of MeAnn proteins ranged from 24.66 (MeAnn2) to 50.62 (MeAnn6), with six MeAnns (MeAnn2, 3, 7, 8, 11, and 12) denoted as stable proteins, while the other six MeAnns are unstable proteins. The Al (aliphatic index) of the MeAnns ranged from 80.14 (MeAnn10) to 100 (MeAnn7) (Table 1). Signal peptide (SP) analysis showed that only one of the twelve MeAnns (MeAnn6) has a signal peptide (Table 1). Subcellular localization prediction indicated that the MeAnns are located in one to three organelles including the cytoplasm (Cytop), mitochondria (Mito), nucleus (Nuc), chloroplast (Chlo) and plasma membrane (Plasm). Most MeAnns have two subcellular localization organelles. For example, MeAnn1 is located in the cytoplasm and mitochondria; MeAnns2, 3, 7 and 8 are located in the cytoplasm and nucleus; MeAnn4 is located in the mitochondria and chloroplast; MeAnn6 is located in the plasma membrane and nucleus; and MeAnn10 is located in the mitochondria and nucleus. MeAnn5 and MeAnn12 are located in three organelles, including the cytoplasm, mitochondria and nucleus, whereas MeAnn9 and MeAnn11 are only located in the mitochondria (Table 1).

\section{Location and Distribution of MeAnns on Chromosomes}

Using chromosomal localization analysis, the $12 \mathrm{MeAnn}$ genes were assigned to eight chromosomes, including 4, 6, 9, 11, 12, 15, 17, and 18 (Fig. 1). The distribution of MeAnns among the chromosomes is unequal. In particular, chromosomes 4 and 11 harbor 6 MeAnns, with each one containing three genes. By contrast, chromosomes 6, 9, 12, 15, 17 and 18 each harbor only one MeAnn gene (Fig. 1). MeAnn1, 2, 5 and 6 have the same orientation, whereas the other MeAnnsare in the opposite orientation.

\section{Cassava MeAnn Sequence Alignment}

To obtain detailed information on each cassava MeAnn protein, the 12 MeAnn proteins were subjected to multiple sequence alignment (Fig. 2.) All of the MeAnns contain typical annexin domains with four 70amino acid repeats (Repeats $\mathbb{\nabla}-\mathbb{\text { }}$ ). The type $\otimes \mathrm{Ca}^{2+}$ binding sites appear in both Repeats $\otimes$ and $\otimes$. Only MeAnn7 and 8 have typical G-X-GTD-\{38 residues\}-E/D sites. The "G-X-GTD" is changed to "G-X-GTN" in MeAnn1-4; to "G-X-GVD" in MeAnn5 and 6; and to "G-X-GCD" in MeAnn9, 11 and 12. The typical G-X-GTD- 
\{38 residues\}-E/D site is missing from MeAnn10 (Fig. 2). MeAnns 1-4 and 10 contain a phospholipid binding-related "W" residue in Repeat $\triangle$ (Fig. 2). All the MeAnns except MeAnns 5-7 and 10 contain a peroxidase activity-related heme-binding site ("H" residue) (Fig. 2). MeAnn1, 2, 7 and 8 contain the typical GTP-binding site "DXXG" in Repeat $\mathbb{\mathbb { N }}$; however, the " $D$ " residue is changed to " $E$ " in MeAnns 3, 4, 9, 11 and 12; to "N" in MeAnns 5 and 6; and to "A" in MeAnn10 (the "DXXG" is changed to "AXXXG") (Fig. 2).

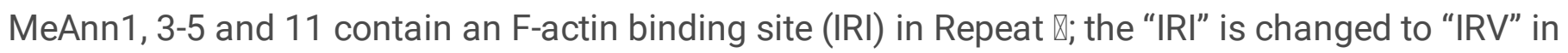
MeAnn2, to "VRI" in MeAnn6, to "VYI" in MeAnn7, to "VYV" in MeAnn8, to "IQI" in MeAnn9 and 12, and to

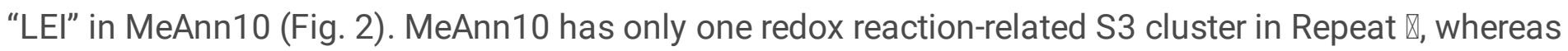

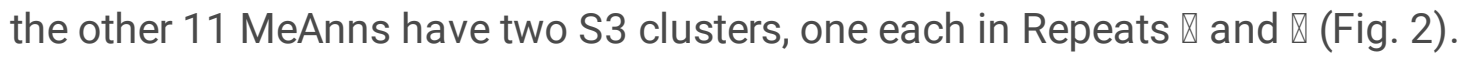

\section{Phylogenesis Analysis, Gene Structures and Conserved Motifs in cassava MeAnns}

To make clear the relationships among theMeAnn members in cassava, a phylogenetic tree consisting of all the annexins from $M$. esculeta, $A$. thaliana, $O$. sativa and $S$. lycopersicum was framed using the Neighboring-Joining method. The results showed that the MeAnns in the phylogenetic tree are classified

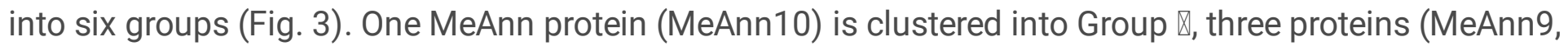
11 and 12) are clustered into Group $\otimes$, MeAnn5 and 6 are clustered into Group $\nabla$, MeAnn 7 and 8 are clustered into Group $\nabla$, MeAnn3 3 and 4 are clustered into Group $\varangle$, and MeAnn1 and 2 are clustered into

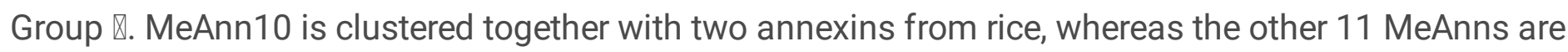
clustered together with annexins from Arabidopsis, rice and tomato (Fig. 3).

The gene structures of the annexin members in cassava and Arabidopsis were determined using the GSDS online tool. The genomic DNA lengths of MeAnn genes vary from 1586 to $3162 \mathrm{bp}$, which are longer than their orthologs from Arabidopsis. However, their CDS lengths vary from 930 to 1149 (bp), which are similar to their orthologs from Arabidopsis (Table 1, Fig. 4B). The MeAnn gene structures have four ( MeAnn10) to seven ( MeAnn4) exons that are interrupted by three to six gene-specific introns with



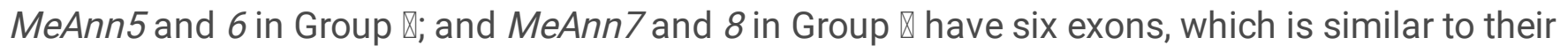
orthologs from Arabidopsis (Fig. 4A, B). In Group $\otimes$, the structure of MeAnn3 is similar to its ortholog

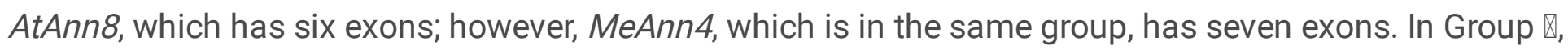
MeAnn1 and 2 each have five exons, which is similar to AtAnn2, though it is different from AtAnn 16 and 7 in the same group. Only one gene (MeAnn10) in Group $\mathbb{Q}$ has four exons in its structure (Fig. 4A, B).

Ten different conserved motifs were identified from MeAnns and AtAnns (Fig. 3 C). Generally speaking,

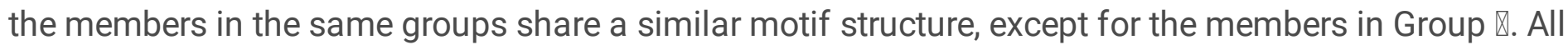

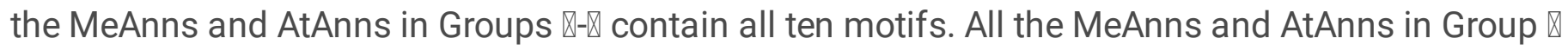

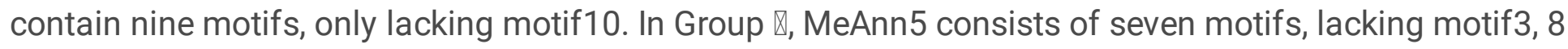
and 9, and MeAnn6 includes eight motifs, lacking motif3 and 8. By contrast, AtAnn4, which is also in 


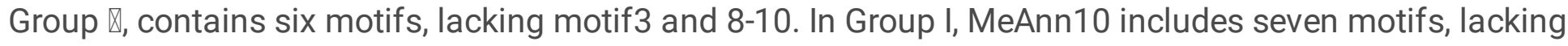
motif5, 6 and 8 (Fig. 3A, C).

\section{Presence of hormone- and stress-related cis-acting elements in the MeAnn promoter}

To better understand the feasible biological responses of MeAnns under hormone and abiotic stresses, the $2 \mathrm{~kb}$ sequence upstream of the translation start site of each MeAnn was analyzed by PlantCARE. Twelve hormone response cis-elements, including an ABRE, ABRE4, as-1, CCTCA motif, ERE, GARE motif, TATC box, TCA, TCA element, TGA box, TGA element and TGACG motif, were predicted (Fig. 4, Table S1). Fifteen stress response cis-elements, including an ARE, RDE core, LTR, MBS, Myb, MYB recognition site, MYB, Myc, MYC, STRE, TC-rich repeats, W box, WRE3, and WUN motif, were predicted (Fig. 4). MeAnns possess at least 3 hormone response-related cis-elements and 1 stress response-related cis-element, which indicates that MeAnn expression might be regulated by these hormone and abiotic stress factors. All twelve MeAnns contain one to seven EREs, suggesting potential responses to ethylene. One to four ABREs are present in nine MeAnns (except MeAnn9, 10 and 12) and one to two ABRE4s are present in MeAnn1, 2, 6, 7 and 11, which indicates that these genes might be regulated by ABA. One to three CGTCA motifs and TGACG motifs are found in three genes ( MeAnn1, 4 and 9), indicating that these genes might respond to MeJA. Four genes ( MeAnn 4, 6, 7 and 17) contain a GARE motif and five genes ( MeAnn1, 4, 10-12) contain a TATC box, figuring that these MeAnns might be adjusted by gibberellin (GA). Eight genes (except for MeAnn1, 2, 4 and 12) have TCA or TCA elements that might respond to salicylic acid (SA). The five genes ( MeAnn4, 5, 8, 9 and 11) with a TGA box or TGA element might respond to auxin. The genes ( MeAnn 1, 4 and 9) with an as-1 cis-element may respond to auxin, salicylic acid and methyl jasmonate (JA). All the genes contain Myb, MYB, or MYB recognition sites, which indicates that all MeAnns might be regulated by MYB transcript factors. All the MeAnns except MeAnn3 have Myc or MYC sites. Nine MeAnns, except for MeAnn9, 10 and 12, show ARE motifs, which are cis-acting regulatory elements important for anaerobic induction. MeAnn5, 8 and 9 contain a DRE core, which is a cis-acting element related to dehydration, low temperature, and salt stress responses. MeAnn1, 8, 9 and 11 contain an LTR motif, which is a cis-acting element involved in low temperature responsiveness. MeAnn3, 5, 8, 9 and 11 contain an MBS, which is a MYB binding site related to drought-inducibility. MeAnn4-10 and 12 contain one to four stress-responsive elements (STREs). MeAnn2, 3 and 12 contain one to two cis-acting responsive elements related to defense and stress responsiveness (TC-rich repeats). Except for MeAnn9, all the other MeAnns have at least one wound-responsive element (WRE3, W box or WUN motif). Among the hormone-associated cis-elements, ERE is the most abundant and ABRE is second. Among the stressrelated elements, MYB- and MYC-associated cis-elements are the most abundant, followed by woundresponsive elements. 


\section{Analysis of Tissue-Specific Expression Patterns of the 12 MeAnns}

To evaluate the tissue specific expression levels of the MeAnns, RNA-seq data were downloaded from $\mathrm{NCBI}$ and analyzed. The gene expression levels of the $12 \mathrm{MeAnns}$ were analyzed in a variety of the organs or tissues in cassava, such as leaves, stems, fiber roots, storage roots, midveins, lateral buds, OES, FEC, petioles, RAM, and SAM. The results, which are shown in a heatmap, indicated that some MeAnns are expressed in all detected organs or tissues, suggesting that these genes may have essential biological roles in cassava growth and development. For instance, MeAnn 1, MeAnn2 and MeAnn5 exhibited very high expression levels in all the tested organs or tissues. Their expression in young tissues, such as RAM and SAM, is higher than in mature organs, such as the leaves and roots. By contrast, MeAnn 12 exhibits very low levels in all of the tested organs or tissues. The other genes exhibit varying expression patterns (Fig. 6). The expression patterns of MeAnns in leaves and midveins are similar; aside from MeAnn4 and MeAnn12, the other MeAnns are highly expressed.Moreover, MeAnn expression patterns in lateral buds and s hoot apical meristems are similar; aside from MeAnn12, the other eleven MeAnns are highly expressed. The MeAnn expression patterns in fibrous roots are similar to that in root apical meristems, which show lower expression levels. The MeAnn expression patterns in stems and petioles are similar. The MeAnn expression patterns vary in other organs or tissues such as somatic organized embryogenic structures, friable embryogenic calli and storage roots (Fig. 6).

\section{Examination of MeAnn gene expression under cold, drought and salt stresses}

To uncover the changes in MeAnn expressionin response to cold, drought and salt stress, the relative expressions of the $12 \mathrm{MeAnns}$ were analyzed by qRT-PCR under $4{ }^{\circ} \mathrm{C}, 20 \%$ PEG6000 and $300 \mathrm{mmol} / \mathrm{L}$ $\mathrm{NaCl}$ treatments, respectively, at different time points (from 0 to $48 \mathrm{~h}$ ). The results indicated varied MeAnn expression profilesafter cold, drought, and salinity treatments (Fig. 7-9). Most obviously, MeAnn5 and 9 were more sensitive to the three stresses (Fig. 7-9).

When cassava seedlings were under $4^{\circ} \mathrm{C}$ cold stress, MeAnn5, 6 and 9 were significantly upregulated in leaves; MeAnn 1 and 10 were suppressed at all six cold stress stages; MeAnn2 was downregulated at all stages except $9 \mathrm{~h} ;$ MeAnn3 was downregulated at 9, 12 and $48 \mathrm{~h} ;$ MeAnn4 was upregulated at 3, 6 and 24 $\mathrm{h} ;$ MeAnn 7 was upregulated at $9 \mathrm{~h}$ and downregulated at $12 \mathrm{~h} ;$ MeAnn11 was only significantly upregulated at $9 \mathrm{~h}$; and MeAnn12 was downregulated at 9 and $12 \mathrm{~h}$ (Fig. 7). In shoots, MeAnn1 was downregulated at 9 and $12 \mathrm{~h} ; M e A n n 2$ was upregulated at 9 and $12 \mathrm{~h} ; M e A n n 4$ was upregulated at $9 \mathrm{~h}$; MeAnn5 and 6 were upregulated at $9 \mathrm{~h}$; MeAnn 7 was downregulated at 24 and $48 \mathrm{~h}$; MeAnn 8 was downregulated at $12 \mathrm{~h} ;$ MeAnn 9 was upregulated at $6 \mathrm{~h}$ and downregulated at 9, 12 and $24 \mathrm{~h} ;$ MeAnn10 was upregulated at 3, 9, 12, 24 and $48 \mathrm{~h} ;$ MeAnn11 was markedly upregulated at 3 and $12 \mathrm{~h}$; and MeAnn12 was upregulated at 6, 24 and $48 \mathrm{~h}$. The differential expression of MeAnn3 was weaker at all the 
stages under cold stress (Fig. 7). In roots, MeAnn1, 9 and 12 were significantly downregulated under cold stress at all six stages. Moreover, MeAnn2 was upregulated at $12 \mathrm{~h} ; \mathrm{MeAnn} 7$ was upregulated at 12 and $48 \mathrm{~h} ;$ MeAnn4 was downregulated at 9, 12, 24 and $48 \mathrm{~h} ;$ MeAnn10 was downregulated at 3, 6, 9 and $24 \mathrm{~h}$; and MeAnn 11 was downregulated at $24 \mathrm{~h}$ cold stress. MeAnn3, 5, 6 and 8 showed weaker differential expression under cold stress than under control conditions (Fig. 7).

When the cassava seedlings were under 20\% PEG drought stress, in leaves, MeAnn4-6 and 9 were markedly upregulated, MeAnn2 and 10 were downregulated at all time points; MeAnn 8 and 11 were upregulated at $3 \mathrm{~h}$; the expression of MeAnn 7 was markedly upregulated at 3, 6 and $12 \mathrm{~h}$; MeAnn 12 was upregulated at $12 \mathrm{~h}$; and MeAnn1 was significantly downregulated at 9 and $48 \mathrm{~h}$ (Fig. 8). In shoots under drought stress, MeAnn 1, 5 and 9 were downregulated at all time points; MeAnn6, 7 and 10 wereupregulated at $3 \mathrm{~h}$; MeAnn 1 was downregulated and MeAnn10 was upregulated at $6 \mathrm{~h}$; and all the other genes had weaker differential expression at the six time points (Fig. 8). In roots, at 3 and $6 \mathrm{~h}$, only MeAnn2 was distinctly downregulated; at $9 \mathrm{~h}$, only MeAnn6 was distinctly upregulated; at $12 \mathrm{~h}, \mathrm{MeAnn} 2$, 6, 7, 10 and 11 were upregulated and MeAnn 9 and 12 were downregulated; and at 24 and $48 \mathrm{~h}$, only MeAnn12 was distinctly downregulated (Fig. 8).

When the cassava seedlings were under $300 \mathrm{mmol} / \mathrm{L} \mathrm{NaCl}$ stress, in leaves, MeAnn5-7 and 9 were markedly upregulated, MeAnn2 and 10 were downregulated at all time points; MeAnn4 was upregulated from 3-24 h; MeAnn11 expression was markedly upregulated at 24 and $48 \mathrm{~h}$; and MeAnn1 was significantly downregulated at $12 \mathrm{~h}$ (Fig. 9). In shoots, all 12 MeAnns had weak differential expression at 3 and $48 \mathrm{~h} ; M e A n n 1,7$ and 9 were downregulated at $6 \mathrm{~h} ; M e A n n 4$ and 12 were upregulated at $9 \mathrm{~h}$; MeAnn1, 3-5, 8 and 9 were significantly downregulated and MeAnn7 and MeAnn10 were upregulated at $12 \mathrm{~h}$; and MeAnn4 was upregulated at $24 \mathrm{~h}$ (Fig. 9). In roots, all the MeAnns had slightly lower differential expression compared to the control at $3 \mathrm{~h}$; only MeAnn 1 was upregulated at $6 \mathrm{~h} ; \mathrm{MeAnn} 4$ and 7 were upregulated at $9 \mathrm{~h} ; \mathrm{MeAnn1}, 6$, 7,and 9-11 were upregulated and MeAnn2 and 8 were downregulated at 12 h; MeAnn 1, 7, 9 and 10 were upregulated at 24 h; and MeAnn1 and 9 were upregulated at $48 \mathrm{~h} \mathrm{(Fig.} \mathrm{9).}$

\section{Examination of MeAnn gene expression in response to $\mathrm{Ca}^{2+}$ signaling and hormones by $\mathrm{qRT}-\mathrm{PCR}$}

To reveal the responses of the MeAnns to $\mathrm{Ca}^{2+}$ signaling, the cassava seedlings were treated with different concentrations of $\mathrm{CaCl}_{2}$. The results indicated that $M e A n n 1,2$ and 10 were downregulated, while MeAnn5 and 9 were upregulated in leaves under all the $\mathrm{CaCl}_{2}$ treatments. MeAnn6 and 7 had similar expression patterns in leaves under $\mathrm{CaCl}_{2}$ treatments. MeAnn 1 and 9 had similar expression patterns and were downregulated under all treatments in shoots. MeAnn3, 4, 8 and 12 were downregulated under 20 $\mathrm{mmol} / \mathrm{L} \mathrm{CaCl}_{2}$ treatment in shoots. MeAnn 1 and 9 as well as MeAnn 4 and 12 had the same expression patterns in roots, which were downregulated under $\mathrm{CaCl}_{2}$ treatments. $\mathrm{MeAnn2}$ was upregulated under 10, 20 and $50 \mathrm{mmol} / \mathrm{L} \mathrm{CaCl}_{2}$ treatments in roots. MeAnn6 and MeAnn7 were upregulated in roots under 50 
$\mathrm{mmol} / \mathrm{L}$ and 10, 40 and $50 \mathrm{mmol} / \mathrm{L} \mathrm{CaCl}_{2}$ treatments, respectively. MeAnn10 and 11 were upregulated under the $40 \mathrm{mmol} / \mathrm{L} \mathrm{CaCl}_{2}$ treatment in roots. MeAnn3 and MeAnn8 were downregulated under 40 $\mathrm{mmol} / \mathrm{L}$ and 20 and $30 \mathrm{mmol} / \mathrm{L} \mathrm{CaCl}_{2}$ treatment in roots, respectively (Fig. 10).

In leaves under ABA treatment, MeAnn4 and 11 were upregulated and MeAnn 10 and 12 were downregulated. MeAnn4-6 and 9 were upregulated and MeAnn2 and 10 were downregulated by GA and JA treatments. MeAnn4 and 6 were upregulated and MeAnn9, 10 and 12 were downregulated by SA treatments. In shoots, MeAnn 9 was downregulated by ABA treatment. MeAnn7 and 8 were upregulated by GA treatment. MeAnn9 and 12 were upregulated by JA treatment. All the MeAnns in shoots were weakly responsive to SA treatment. In roots, MeAnn2 and 9 were downregulated, while MeAnn4, 6 and 8 were upregulated by ABA treatment. MeAnn9 was downregulated by the ABA, GA, JA and SA treatments. MeAnn 1 was downregulated by JA treatment, MeAnn2 was downregulated by ABA treatment, MeAnn3 was upregulated by SA treatment, MeAnn 4 was upregulated by ABA and SA treatments, MeAnn 6 and 8 were upregulated by ABA treatment, and MeAnn 11 was downregulated by SA treatment. MeAnn5, 7, 10 and 12 showed slight responses to the four hormones (Fig. 11). Among all the MeAnns, MeAnn9 showed an obvious up- or down-regulated response to most of the hormones in different tissues.

\section{Discussion}

Annexin genes have been reported to play significant roles in plant growth, development, and overcoming abiotic adversity [27-37]. Numerous annexin family gene members have been identified in other plants. For instance, 8 Annexins from Arabidopsis [27], nine Annexins from tomato [33], 10 Annexins from rice $[12,38]$, and 12 Annexins from maize [39] have been reported. In this study, 12 Annexin genes from cassava have been identified and characterized (Table 1). MeAnns in cassava are classified into six welldelimited clusters (Fig. 3). The subcellular distribution profile of annexin proteins is one of the key factors associated with their functions. Previous studies indicated that plant annexin localization sites vary, including the cytoplasm, plasma membrane, nucleus, nucleolus and extracellular matrix [19, 34, 40, 41]. For instance, the Apium graveolens annexin gene $\mathrm{VCaB} 42$ was detected to localize in vacuole membranes [41]. The AnnSp2from Solanum pennellii was localized in the nucleus [34], whereas GhFAnnxA in Gosyypium hirsutum was reported to be localized in the cytoplasmic-nuclear region [42]. Previous studies have also demonstrated that plant annexins show dynamic and reversible distribution profiles, with their distributions changing between the membrane and cytoplasm under different stress conditions [43-46]. In this study, the subcellular localization of MeAnns were predicted to have five sites including the cytoplasm, mitochondria, nucleus, chloroplast, and plasma membrane. Here, our results are in partial agreement with previous results.

Sequence analysis of the annexin amino acid sequences from cassava shows that the four repeats and some conserved motifs are present in MeAnns. There are two type II calcium-binding sites in the first and fourth annexin repeats, an IRI motif related to actin binding in the third repeat, and a DXXG motif related to GTPase activity in the fourth repeat. These results show the consistency of the annexin protein domains among cassava and other plants reported in other studies (Fig. 2) [12]. It has been reported that 
all annexins have a core domain that is composed of four similar approximately 70 -amino acid repeats [3]. The $\mathrm{C}$-terminal region of the vertebrates annexin contains 4 motif repeats that have a greatly conserved sequence (GxGT-[38 residues]-D/E) for $\mathrm{Ca}^{2+}$ binding [3]. It has been demonstrated that cotton ANXD36 has higher GTPase activity than ATPase activity and is inhibited by calcium due to the presence of the GTPase activity site, such as the DXXG in the fourth repeat [47]. All plant annexins belong to soluble proteins and contain greatly conserved calcium-binding domains and diverse $\mathrm{N}$-terminal regions and lack the long N-terminal regions compared to vertebrates [20]. Analysis of the full-length MeAnn genomic DNA sequences showed a variety of MeAnn gene structures with different numbers of exons and introns (Fig. 4B). Similar results are also found in other plants; for example, AtAnn 1 has two introns, AtAnn6 and 7 have three introns, AtAnn2 has four introns and other AtAnns have five introns [5,6]. Previous studies have indicated that multiple annexin genes could be locate on one chromosome. For example, in Arabidopsis, 4 annexin genes are located on chromosome 5 [38]; in rice, two annexins are locate on chromosome 5 and three are located on chromosome 9 [38]; in poplar, three annexin genes are located on chromosome 1[38]; and in Zea mays, three annexin genes, MeAnn7-9, arelocated on chromosome 6 [39]. In cassava, both chromosomes 4 and 11 contain three annexin genes (Fig. 1). Thus, the conserved domain and the DNA structure reveal that MeAnns from M. esculenta belong to the annexin multifamily.

By analyzing the cis-acting elements present in the promoters, the possible biological functions of genes can be roughly inferred. In this study, the results indicate that MeAnn promoter regionspossess at least 3 hormone response-related cis-elements and 1 stress response-related cis-element [Fig. 5]. The stress- or hormone-related cis-acting elements also have been reported to exist in other annexin gene promoters. In maize annexin gene promoters, numerous of cis-elements, including ABRE, DRE, and LTRE, related to abiotic stress responses were found [39]. Hormone-related cis-elements, such as ABA, GA, or auxin recognition sites, and stress-related cis-acting elements, such as MYC or MYB recognition sites, were also found in the promoters of tomato annexins [33]. Hormone or stress treatments inducing the expression of annexin genes have been reported in Indian mustard [11], tomato (Solanum pennellii) [32], Arabidopsis $[43,48]$, and alfalfa [49]. The expression of annexin genes induced by auxin [50], SA [51], and methyl jasmonate (JA) [11] have also been reported. Here, at least one stress treatment was found to enhance the expression of several cassava annexin genes (Fig. 7-11). For instance, the expression of MeAnn4, MeAnn6, and MeAnn8 in roots as well as MeAnn4 and MeAnn11 in leaves was highly enhanced by ABA treatment (Fig. 11). In cassava leaves, the expression of MeAnn4-7 and MeAnn9 was highly enhanced by GA and JA (Fig. 11), while the expression of MeAnn4 and MeAnn6 was enhanced by SA treatment (Fig. 11). However, it is hard to speculate the exact expression characteristics of a particular gene based only on cis-acting element analysis. For instance, nine MeAnn promoter regions contain putative ABAresponsive elements. However, in this study, only MeAnn4, MeAnn6, MeAnn8 and MeAnn11 were significantly enhanced by ABA (Fig. 5 and Fig. 11). JA-related cis-elements are found in the promoters of three MeAnns, MeAnn1, 4 and 9. However, the expression of only five MeAnns, MeAnn4-7 and MeAnn9, were highly enhanced by JA (Fig. 5 and Fig. 11). GA-related cis-elements are found in the promoters of seven MeAnns, though the expression of only five MeAnnswere highly enhanced by GA (Fig. 5 and Fig.

Page $11 / 33$ 
11). Eight MeAnns contained SA-related cis elements, but the expression of only three MeAnn genes were highly induced by SA (Fig. 5 and Fig. 11). Similar results were also reported in tomato annexins [33]. Therefore, it is necessary to verify the functions of genes through detailed experiments.

The expression patterns of annexins in plant tissues or organs have been reported in a number of plant species. For instance, in Arabidopsis, AtAnn1 was demonstrated to specifically express in mature pollen and germinated pollen $[52,53]$. In M. trancatula, MtAnn2 has been indicated to express in arbusculecontaining cells in mycorrhizal roots [54]. In Solanum lycopersium, SIAnn4 is specifically expressed during fruit ripening, SIAnn6 is specifically expressed in the stigma or ovary, and SIAnn8 is specifically expressed in the stamen [33]. In Tintorera red grapes, Annexin D1 was observed to express in fresh and raised grape fruits [55]. In soybean, annexin was differentially expressed in suspension-cultured soybean cells [56]. In our study, the expression patterns of MeAnns in 11 cassava tissues were detected [Fig. 7]. The heatmap showed that MeAnn1, MeAnn2 and MeAnn5 exhibit very high levels of expression in all the tested organs or tissues. By contrast, MeAnn12 exhibits very low levels in whole of the detected organs or tissues. In leaves and midveins, all the MeAnns except MeAnn4 and MeAnn12 are highly expressed. In lateral buds and s hoot apical meristems, all the MeAnns except MeAnn12 are highly expressed. The MeAnn expression patterns in fibrous roots are similar to those in root apical meristems, showing that their expression levels are lower than in other tissues. The MeAnn expression patterns in stems and petioles are also similar. By contrast, MeAnn expression patterns are differential in the remaining organs or tissues, such as OES (somatic organized embryogenics), FEC (friable embryogenic callus) and SR (storage roots) (Fig. 6).

Gene expression of annexin genes, in response to abiotic stresses such as drought, salt and cold, have been studied in some plants [27, 44, 48, 57]. In M. sativa, the annexin MsAnn2 was observed to respond to salt and drought stresses [48]. Arabidopsis transcriptome analysis reported that annexins were upregulated under salt, cold and osmotic stresses [57]. This analysis showed that AtAnn1i AtAnn6 and AtAnn 8 showed significantly increased expression in Arabidopsis under salt and dehydration stresses [27]. Subsequently, AtAnn1 was intensively studied to reveal its major role in drought stress tolerance [10]. AtAnn 1 and AtAnn 4 were also revealed to interact with one another and in a light-dependent manner to regulate salt and drought stresses [23]. The role of AtAnn8 in Arabidopsis salt and dehydration tolerance was also confirmed in a recent study [58]. In wild tomato, researchers have demonstrated that SpUSP functions in association with SpAnn2 in drought stress signaling [59]. Overexpressing SpAnn2 could enhance the salt and drought tolerance of transgenic tomato plants [34]. In rice, OsAnn1 was reported to be associated with heat stress [44], while OsAnn3 was reported to be associated with cold stress [36]. In our study, MeAnn5 and MeAnn9 in leaves were significantly upregulated by cold, drought and salt stresses (Fig. 7-9). Interestingly, the MeAnn expression patterns under cold stress were more similar to the expression patterns under $\mathrm{CaCl}_{2}$ than under drought and salt stresses (Fig. 7-10). MeAnn5, 6 and 9 were significantly upregulated, while MeAnn 1 and 10 were downregulated at all six time points during cold stress to cassava leaves. In roots, MeAnn 1, 9 and 12 were significantly downregulated under cold stress at all six time points (Fig. 7). MeAnn4-6 and 9 were significantly upregulated, while MeAnn2 and 10 were 
downregulated under PEG-induced drought stress in leaves (Fig. 8). MeAnn5-7 and 9 were significantly upregulated, while MeAnn2 and 10 were downregulated under salt stress from 3-48 hours in cassava leaves (Fig. 9). Unlike the MeAnn gene responses to low temperature, no increase was observed in the transcription of any rice annexin genes in response to low temperature treatment, although decreased relative expression of OsAnn2 and OsAnn 10 was observed in the untreated control [12]. In wheat, Breton et al. (2000) identified that there are four annexins that respond to low temperatures; they also showed their association with the membrane, but that this interaction was calcium-independent [8]. Gene expression of Annexin genes in response to drought has also been studied in Arabidopsis, which was also subject to oxidation-driven post-translational regulation [10]. Compared with the untreated control, the expression of OsAnn6 and OsAnn7 showed significant upregulation in response to $\mathrm{NaCl}$ treatment, while the expression of OsAnn1 and OsAnn10 showed a significant decrease under the same salt treatment [12]. The comparative discussion of expression patterns among cassava and other plants indicates that MeAnns from cassava can respond to abiotic stresses, though with specific patterns for each gene, which are similar with other plants.

\section{Conclusions}

In this paper, annexin genes were searched in the cassava genome, systematically characterized and examined for their relationships and expression analysis. Twelve MeAnn genes were identified in the cassava genome. All MeAnns contain typical annexin domains. The MeAnns were classified into six groups. All the MeAnns contain hormone or stress response-related cis-elements in their promoter regions. MeAnn1, MeAnn2 and MeAnn5 exhibit very high levels of expressions in all the detected organs or tissues. By contrast, MeAnn12 exhibited very low levels in all the detected organs or tissues. Expression pattern analysis under abiotic stresses suggests that MeAnn5 and MeAnn9 have positive responses to abiotic stresses and calcium signaling and are induced by GA and JA in cassava leaves, while MeAnn2 and MeAnn10 have the opposite expression patterns under the same stresses. The expression patterns of MeAnns under abiotic stresses are irregular in shoots. In roots, MeAnn1 and MeAnn9 have the similar expression patterns, as both are downregulated by cold, $\mathrm{CaCl}_{2}$ and $\mathrm{JA}$ treatments, while the remaining genes display irregular expression patterns. These results will promote the subsequent functional investigations and the utilization of MeAnns in cassava and other plants.

\section{Methods}

\section{Identification and Characterization of MeAnns from Cassava}

To identify the annexin members in the cassava genome, the eight known annexins members AtAnn1-8 from $A$. thaliana were used as probes for BLASTP of the M. esculenta V6.1 database. The MeAnn protein 
sequences were further analyzed with the Pfam [60]and SMART[61] online tools. The physiological and biochemical characteristics of the MeAnn proteins, such as the molecular weight (MW), theoretical isoelectric point ( $\mathrm{pl}$ ), and hydrophilic mean (GRAVY), were analyzed with the ProtParam online tool [62]. The prediction of MeAnn protein subcellular location was performed with the CELLO2GO online tool[63].

\section{Analysis of the Location and Distribution of MeAnns on Cassava Chromosomes}

The chromosomal localization of each MeAnn gene and the chromosome sizes were obtained from the cassava open genome database (Bioproject: PRJNA234389). Then, the Mapinspect software (Mike Lischke, Berlin, Germany) was utilized to map the chromosomal localizations of the MeAnn genes. The Photoshop software CS (San Jose, CA, USA) was utilized to beautify and enrich the image.

\section{MeAnn Phylogenetics, Structures and Motifs}

The annexin protein sequences from cassava, Arabidopsis, rice and tomato were collected and multialigned with ClustaIW. Then, a phylogenetic tree was produced using the MEGA7.0 software and based on the neighbor-joining method [64]. The AtAnn and MeAnn gene structureswere determined with the GSDS online software [65]. The MeAnn motifs were identified with the MEME Suite 4.12.0 online tool [66].

\section{Analysis of the MeAnn Promoter Cis-Elements}

To understand the cis-element distribution in the MeAnn promoters, 2000-bp sequences upstream of the initiation codon (ATG) of each MeAnn genewere downloaded from the public cassava genome database. The cis-elements in the MeAnn gene promoters were identified by searching the PlantCARE database website (http://bioinformatics.psb.ugent.be/webtools/plantcare/html/). The data were counted and processed with Microsoft Office Excel (One Microsoft Way, Redmond, WA98052-6399) to create tables and graphs.

\section{MeAnn Expression Patterns in Cassava}

To study the expression levels of the MeAnns in different organs and tissues of cassava, the expression data for the 12 MeAnns were downloaded from the public RNA-seq data of cassava (Bioproject ID PRJNA324539). The eleven different organs and tissues in cassava included the leaf, petioles, midveins, stems, shoot apical meristems (SAMs), lateral buds, fibrous roots, storage roots, root apical meristems (RAMs), somatic organized embryogenics (OES), and friable embryogenic calli (FEC). The heatmap was created with the OmicShare tools online (http://www.omicshare.com/tools). 


\section{Plant Materials and Treatments}

The cassava cultivar SC8 was supplied by Cassava Research Center of the Tropical Crops Genetic Resources Institute, Chinese Academy of Tropical Agricultural Science. Thirty-day-cultivated SC8 cassava seedlings were individually placed in a $4^{\circ} \mathrm{C}$ incubator for cold stress, in $300 \mathrm{mmol} / \mathrm{L} \mathrm{NaCl}$ solution for salt stress, and in a $20 \%$ PEG-simulated dry environment for drought stress treatments. The samples were harvested at the treatment stages of $0,3,6,9,12$ and $24 \mathrm{~h}$, separately. The 30-day SC8 seedlings were individually placed in $50 \mu \mathrm{mol} / \mathrm{L}$ IAA solution, $2 \mathrm{mmol} / \mathrm{L}$ SA solution, $100 \mu \mathrm{mol} / \mathrm{L} \mathrm{GA}_{3}$ solution, 100 $\mu \mathrm{mol} / \mathrm{L}$ JA solution, and $100 \mu \mathrm{mol} / \mathrm{L}$ ABA solution for $12 \mathrm{~h}$ for the hormone treatments. The 30 -day SC8 seedlings were individually placed in $10,20,30,40$ and $50 \mathrm{mmol} / \mathrm{L} \mathrm{CaCl}_{2}$ for $12 \mathrm{~h}$ for the calcium treatments. The 30-day SC8 seedlings treated with $\mathrm{H}_{2} \mathrm{O}$ were employed as blank controls. Each treatment was performed with three biological replicates. Collected cassava leaf, root and stem samples were outright frozen in liquid nitrogen and then saved at $-80{ }^{\circ} \mathrm{C}$ until the follow-up experiments.

\section{Total RNA isolation and qRT-PCR analysis}

A RNAplant plus (TIANGEN, China) was used to extract total RNA from cassava. A PrimeScript RT reagent kit with gDNA Eraser (Takara, Japan) was used to synthesize the first CDNA chain. qPCR SYBR Premix Ex Taq II (Takara, Japan) was used to conduct qRT-PCR analysis in a ABI 7900HT Fast Real-Time PCR System ( $A B I, U S A)$. The relative expression levels of the MeAnn genes were evaluated by the $2^{-} \triangle \triangle C t$ method and normalized by log2 values. The normalized relative expression data were used to construct a heatmap. Three technical replicates were settled. The qRT-PCR primers are listed in Table S2.

\section{Abbreviations}

GA: gibberellin ; JA: jasmonic acid; Ann:annexin gene; CBS: calcium binding sites; AA : amino acids; MW: molecular weights; GRAVY: grand average of hydropathicity; PL: Protein length; MW: Molecular weight of the amino acid sequence; GRAVY: grand average of hydropathicity; pl: theoretical isoelectric point; II: Instability index; Al: Aliphatic index; S: stable; U: unstable; Cytop: cytoplasm; Mito: mitochondria; Nuc: nucleus; Chlo: chloroplast; and Plasm: plasma membrane; OES: the somatic organized embryogenics; FEC: the friable embryogenic calli; FR: the fibrous roots; SR: storage roots; RAM: the root apical meristems; and SAM: shoot apical meristems.

\section{Declarations}

\section{Ethics approval and consent to participate}

Not applicable 


\section{Consent to publish}

All of the authors consent to publish this article.

\section{Availability of data and materials}

Not applicable

\section{Competing interests}

The authors declare that they have no competing interests.

\section{Funding (State the role of the funding body on the study)}

This research was funded by The National Key Research and Development Program of China (2018YFD1000500); the National Natural Science Foundation of China (No.31601359; 31600196 and 31671767), and the Earmarked Fund for China Agriculture Research System (No.CARS-11-HNGJC).

\section{Authors' Contributions}

$\mathrm{RL}$ and $\mathrm{YH}$ were responsible for all aspects of the research, including experimental design, data acquisition and analysis, and manuscript preparation. YW, YZ, and TQ worked on the preparation of the studied materials, and qRT-PCR. YS, YY, JL and SF worked on primer design, and technical and informatics analyses of these genes. XH and JG were responsible for the programs and all experiments, critically revised the manuscript, and provided the final approval of the article.

\section{Acknowledgements}

We fully appreciate the editors and all anonymous reviewers for their constructive comments on this manuscript.

\section{References}

1. Talukdar T, Gorecka KM, De CF, Downie JA, Cullimore J, \& Pikula S. Annexins - calcium- and membrane-binding proteins in the plant kingdom: potential role in nodulation and mycorrhization in medicago truncatula. Acta Biochimica Polonica. 2009;56(2):

2. Clark GB, Morgan RO, Fernandez MP, \& Roux SJ. Evolutionary adaptation of plant annexins has diversified their molecular structures, interactions and functional roles. New Phytologist.2012;169:695-712. 
3. Moss SE, Morgan RO. The annexins. Genome Biology. 2004;5(4), 1-8.

4. Morgan RO, Fernández MP. Molecular phylogeny of annexins and identification of a primitive homologue in giardia lamblia. Molecular Biology and Evolution. 1995;12(6):967-979.

5. Boustead CM, Smallwood M, Small H, Bowles DJ, \& Walker JH. Identification of calcium-dependent phospholipid-binding proteins in higher plant cells. Febs Letters. 1989;244(2):456-460.

6. Proust J, HoulnÃ G, Schantz ML, \& Schantz R. Characterization and gene expression of an annexin during fruit development in capsicum annuum. Febs Letters. 1996;383(3):208-212.

7. Jézabel P, Guy H, Schantz ML, Shen WH, Schantz R. Regulation of biosynthesis and cellular localization of sp32 annexins in tobacco by 2 cells. Plant Molecular Biology. 1999;39(2):361-372.

8. Breton G, Vazqueztello A, Danyluk J, \& Sarhan F. Two novel intrinsic annexins accumulate in wheat membranes in response to low temperature. Plant \& Cell Physiology. 2000;41(2):177-84.

9. Clark GB, Sessions A, Eastburn DJ, \& Roux SJ. Differential expression of members of the annexin multigene family in arabidopsis. Plant Physiology. 2001;126(3):1072-1084.

10. Konopka-Postupolska D, Clark G, Goch G, Debski J, Floras K, \& Cantero A, et al. The role of annexin 1 in drought stress in arabidopsis. PLANT PHYSIOLOGY. 2009;150(3):1394-1410.

11. Jami SK, Dalal A, Divya K, \& Kirti PB. Molecular cloning and characterization of five annexin genes from indian mustard (Brassica juncea I. czern and coss). Plant Physiol Biochem.2009;47(11):977990.

12. Jami SK, Clark GB, Ayele BT, Roux SJ, \& Kirti PB. Identification and characterization of annexin gene family in rice. Plant Cell Reports. 2012;31(5):813-825.

13. Worden AZ, Lee JH, Mock T, Rouze P, Simmons MP, Aerts AL, et al. Green evolution and dynamic adaptations revealed by genomes of the marine picoeukaryotes micromonas. Science. 2009;324(5924): 268-272.

14. Palenik B, Grimwood J, Aerts A, Rouze P, Salamov A, Putnam N, Dupont C, Jorgensen C, Derelle E, et al. The tiny eukaryote Ostreococcus provides genomic insights into the paradox of plankton speciation. Proc Natl Acad Sci. 2007;104: 7705-7710.

15. Zhu D, Liu Y, Yang X, Yang C, Ma J, Yang X, Qiao J, Wang L, Li J, Zhang C. Low annexin a1 expression predicts benefit from induction chemotherapy in oral cancer patients with moderate or poor pathologic differentiation grade. BMC Cancer. 2013;13.

16. Bharadwaj A, Bydoun M, Holloway R, Waisman D. Annexin A2 heterotetramer: structure and function, International journal of molecular sciences. 2013;14: 6259-6305.

17. Huang Y, Wang J, Zhang L, \& Zuo K. A cotton annexin protein anxgb6 regulates fiber elongation through its interaction with actin 1. PLOS ONE. 2013;8.

18. Richards SL, Laohavisit A, Mortimer JC, Shabala L, Stéphanie MS, \& Shabala S, et al. Annexin 1 regulates the $\mathrm{H}_{2} \mathrm{O}_{2}$-induced calcium signature in Arabidopsis thaliana roots. The Plant Journal. 2014;77(1):10. 
19. Mortimer JC, Laohavisit A, Macpherson N, Webb A, \& Davies JM. Annexins: multifunctional components of growth and adaptation. Journal of Experimental Botany. 2008;59(3):533-544.

20. Winfield MO, Lu C, Wilson ID, Coghill JA, \& Edwards KJ. Plant responses to cold: transcriptome analysis of wheat. Plant Biotechnology Journal. 2010;8(7):749-771.

21. Yamaguchi T, \& Blumwald E. Developing salt-tolerant crop plants: challenges and opportunities. Trends in Plant Science. 2005;10(12):0-620.

22. Yamaguchi-Shinozaki K, \& Shinozaki K. Transcriptional regulatory networks in cellular responses and tolerance to dehydration and cold stresses. ANNUAL REVIEW OF PLANT BIOLOGY. 2006;57(1):781803.

23. Huh SM, Noh EK, Kim HG, Jeon BW, Bae K, \& Hu HC, et al. Arabidopsis annexins annat1 and annat4 interact with each other and regulate drought and salt stress responses. Plant and Cell Physiology. 2010;51(9):1499-1514.

24. Nambisan B. Strategies for elimination of cyanogens from cassava for reducing toxicity and improving food safety. Food \& Chemical Toxicology An International Journal Published for the British Industrial Biological Research Association. 2011;49(3):0-693.

25. Ceballos H, Iglesias CA, Pérez JC, Dixon AGO. Cassava breeding: opportunities and challenges. Plant Molecular Biology. 2004;56(4):503-516.

26. El-Sharkawy MA. Drought-tolerant cassava for africa, asia, and latin america: breeding projects work to stabilize productivity without increasing pressures on limited natural resources. Bioscience.1993;43(7):441-451.

27. Cantero A, Barthakur S, Bushart TJ, Chou S, Morgan RO, \& Fernandez MP, et al. Expression profiling of the arabidopsis annexin gene family during germination, de-etiolation and abiotic stress. Plant Physiology \& Biochemistry.2006;44(1):13-24.

28. Divya K, \& Kirti PB. Expression of a mustard annexin confers abiotic stress tolerance and improved fiber quality in transgenic cotton. Journal of Biotechnology.2008;136(4):S236-S237.

29. Divya K, Jami SK, \& Kirti PB. Constitutive expression of mustard annexin, annbj1 enhances abiotic stress tolerance and fiber quality in cotton under stress. Plant Molecular Biology. 2010;73(3):293308.

30. Zhou ML, Yang XB, Zhang Q, Zhou M, Zhao EZ, \& Tang YX, et al. Induction of annexin by heavy metals and jasmonic acid in Zea mays. Functional \& Integrative Genomics.2013;13(2):241-251.

31. Singh A, Kanwar P, Yadav AK, Mishra M, Jha SK, \& Baranwal V, et al. Genome-wide expressional and functional analysis of calcium transport elements during abiotic stress and development in rice. Febs Journal.2014;281(3):894-915.

32. Harbaoui M, Saad RB, Halima NB, Choura M, \& Brini F. Structural and functional characterisation of two novel durum wheat annexin genes in response to abiotic stress. Functional Plant Biology. 2017;45(5):542-.

33. Lu Y, Ouyang B, Zhang J, Wang T, Lu C, \& Han Q, et al. Genomic organization, phylogenetic comparison and expression profiles of annexin gene family in tomato (solanum lyco 
persicum). Gene. 2012;499(1):14-24.

34. Ijaz R, Ejaz J, Gao S, Liu T, Imtiaz M, \& Ye Z, et al. Overexpression of annexin gene annsp2, enhances drought and salt tolerance through modulation of aba synthesis and scavenging ros in tomato. Scientific Reports. 2017;7(1):

35. Lichocka M, Rymaszewski W, Morgiewicz K, Barymowfiloniuk I, Chlebowski A, Sobczak M, et al. Nucleus- and plastid-targeted annexin 5 promotes reproductive development in arabidopsis and is essential for pollen and embryo formation. BMC Plant Biology. 2018;18(1):183-.

36. Shen C, Que Z, Xia Y, Ning T, Ding L, \& He R, et al. Knock out of the annexin gene osann3 via crispr/cas9-mediated genome editing decreased cold tolerance in rice. Journal of Plant Biology.2017;60(6):539-547.

37. Szalonek M, Sierpien B, Rymaszewski W, Gieczewska K, Garstka M, \& Lichocka M, et al. Potato annexin stann1 promotes drought tolerance and mitigates light stress in transgenic solanum tuberosum I. plants. Plos One. 2014;10(7):

38. Jami SK, Clark GB, Ayele BT, Paula A, Bharadwaja KP, \& Wei S. Genome-wide comparative analysis of annexin superfamily in plants. PLoS ONE. 2012;7(11): e47801.

39. Zhang ZB, Li XL, Han M, \& Wu ZY. Genome-wide analysis and functional identification of the annexin gene family in maize (Zea mays I.). Plant Omics. 2015;8(5):420-428.

40. Deepanker Y, Prasanna B, Israr A, \& Bharadwaja KP. Plant annexins and their involvement in stress responses. Environmental and Experimental Botany. 2018;S0098847218302892.

41. Seals D. A 42-kilodalton annexin-like protein is associated with plant vacuoles. Plant physiology. 1994;106(4):1403-1412.

42. Clark GB, Dauwalder M, Roux SJ. Immunological and biochemical evidence for nuclear localization of annexin in peas. Plant Physiol Biochem. 1998;36(9): 621-627.

43. Zhang F, Jin X, Wang L, Li S, Wu S, \& Cheng C, et al. A cotton annexin affects fiber elongation and secondary cell wall biosynthesis associated with $\mathrm{Ca}^{2+}$ influx, ROS homeostasis, and actin filament reorganization. Plant Physiology. 2016;171(3):1750-1770.

44. Lee S, Lee EJ, Yang EJ, Lee JE, Park AR, Song WH, and Park OK. Proteomic identification of annexins, calcium-dependent membrane binding proteins that mediate osmotic stress and abscisic acid signal transduction in Arabidopsis. Plant Cell. 2004;16:1378-1391.

45. Qiao B, Zhang Q, Liu D, Wang H, \& Zhu Z. A calcium-binding protein, rice annexin osann1, enhances heat stress tolerance by modulating the production of $\mathrm{H}_{2} \mathrm{O}_{2}$. Journal of Experimental Botany. 2015;66(19):5853-5866.

46. Wang X, Ma X, Wang H, Li B, Tang W. Proteomic study of microsomal proteins reveals a key role for arabidopsis annexin 1 in mediating heat stress-induced increase in intracellular calcium levels. Molecular \& Cellular Proteomics. 2015;14(3):686-694.

47. Shin H, Brown R.M. GTPase activity and biochemical characterization of a recombinant cotton fiber annexin. Plant Physiology. 1999;119(3): 925-934. 
48. Leymarie J, Damerval C, Marcotte L, Combes V, \& Vartanian N. Two-dimensional protein patterns of arabidopsis wild-type and auxin insensitive mutants, axr1, axr2, reveal interactions between drought and hormonal responses. Plant and Cell Physiology. 1996;37(7):966-975.

49. Kovács I, Ayaydin F, Oberschall A, Ipacs I, Bottka S, \& Pongor S, et al. Immunolocalization of a novel annexin-like protein encoded by a stress and abscisic acid responsive gene in alfalfa. Plant Journal. 1998:15(2):185-197.

50. Baucher M, Oukouomi Lowe Y, Vandeputte OM, Mukoko Bopopi J, Moussawi J, \& Vermeersch M, et al. NtANN12 annexin expression is induced by auxin in tobacco roots. Journal of Experimental Botany. 2011;62(11):4055-4065.

51. Gidrol X, Sabelli PA, Fern YS, \& Kush AK. Annexin-like protein from Arabidopsis thaliana rescues delta oxyr mutant of escherichia coli from $\mathrm{H}_{2} \mathrm{O}_{2}$ Proceedings of the National Academy of Sciences. 1996;93(20): 11268-11273.

52. Noir S, Bräutigam A, Colby T, Schmidt J, \& Panstruga R. A reference map of the Arabidopsis thaliana mature pollen proteome. Biochem. res. Commun. 2005;337(4):1257-1266.

53. Zou J, Song L, Zhang W, Wang Y, Ruan S, Wu WH. (2009). Comparative proteomic analysis of Arabidopsis mature pollen and germinated pollen. Journal of Integrative Plant Biology.2009;51(5):438-455.

54. Manthey K, Krajinski F, Hohnjec N, Firnhaber C, Pühler A, \& Perlick AM, et al. Transcriptome profiling in root nodules and arbuscular mycorrhiza identifies a collection of novel genes induced during medicago truncatula root endosymbioses. Molecular Plant-Microbe Interactions. 2004;17(10):10631077.

55. Briz-Cid N, Pose-Juan E, Rial-Otero R, Simal-Gándara J. Proteome changes in garnacha tintorera red grapes during post-harvest drying. LWT - Food Science and Technology.2016;69:608-613.

56. Miernyk JA, Jett AA, Johnston ML. Analysis of soybean tissue culture protein dynamics using difference gel electrophoresis. Journal of Proteomics. 2016;130:56-64.

57. Kreps JA, Wu Y, Chang HS, Zhu T, Wang X, \& Harper JF. Transcriptome changes for arabidopsis in response to salt, osmotic, and cold stress. Plant Physiology. 2002;130(4):2129-2141.

58. Yadav BS, Lahav T, Reuveni E, Chamovitz DA, \& Freilich S. Multidimensional patterns of metabolic response in abiotic stress-induced growth of arabidopsis thaliana. Plant Molecular Biology. 2016;92(6): 689-699.

59. Loukehaich R, Wang T, Ouyang B, Ziaf K, Li H, \& Zhang J, et al. Spusp, an annexin-interacting universal stress protein, enhances drought tolerance in tomato. Journal of Experimental Botan. 2012;63(15):5593-5606.

60. Finn RD, Coggill P, Eberhardt RY, Eddy SR, Mistry J, Mitchell AL, Potter SC, Punta M, Qureshi M, Sangrador-Vegas A, et al. The Pfam protein families database: Towards a more sustainable future. Nucleic Acids Res. 2016;44: 279-285.

61. Letunic I, Bork P. 20 years of the SMART protein domain annotation resource. Nucleic Acids Res. 2018;46:493-496. 
62. Gasteiger E, Hoogland C, Gattiker A, Duvaud S, Wilkins M.R, Appel RD, Bairoch A. Protein identification and analysis tools in the ExPASy Server. In The Proteomics Protocols Handbook; John, MW, Ed, Humana Press: New York, NY, USA, 2005:pp. 571-607.

63. Yu CS, Cheng CW, Su WC, Chang KC, Huang SW, Hwang JK, Lu CH. CELLO2GO: A web server for protein subcellular localization prediction with functional gene ontology annotation. PLoS ONE. 2014;9:e99368.

64. Kumar S, Stecher G, Tamura K. MEGA7: Molecular evolutionary genetics analysis version 7.0 for bigger datasets. Mol. Biol. Evol. 2016;33:1870.

65. Hu B, Jin J, Guo AY, Zhang H, Luo J, Gao G. GSDS 2.0: An upgraded gene feature visualization server. Bioinformatics. 2014;31:1296.

66. Bailey TL, Boden M, Buske FA, Frith M, Grant CE, Clementi L, Ren J, Li WW, Noble WS. Memesuite: Tools for motif discovery and searching. Nucleic Acids Res. 2009;37:202-208.

\section{Tables}

Table 1. A list of the twelve MeAnns identified in this study. 


\begin{tabular}{|c|c|c|c|c|c|c|c|c|c|c|c|c|}
\hline GenBank & Locus name & Chromosomal & Genomic position & gDNA & CDS & P L & pI & MW & GRAVY & AI & SP & Subcellular \\
\hline \multirow[t]{2}{*}{ ID } & & location & & (bp) & $(b p)$ & (aa) & & (kDa) & & & & \\
\hline & & & $\left(5^{\prime}-3^{\prime}\right)$ & & & & & & & & & Location \\
\hline \multirow[t]{2}{*}{ MeAnn 1} & Manes.12G135200 & Chr12 & $28973589-$ & 2799 & 951 & 316 & 6.78 & 35.93 & -0.431 & $45.24 \mathrm{U} 91.77$ & - & Cytop, Mito \\
\hline & & & 28976387 & & & & & & & & & \\
\hline MeAnn2 & Manes.18G068000 & Chr18 & $5847458-5849722$ & 2265 & 951 & 316 & 6.34 & 36.03 & -0.517 & $24.66 \mathrm{~S} 89.56$ & - & Cytop, Nuc \\
\hline \multirow[t]{2}{*}{ MeAnn3 } & Manes.04G165300 & Chr04 & $28577361-$ & 1895 & 945 & 314 & 8.28 & 36.24 & -0.454 & $38.97 \mathrm{~S} 96.88$ & - & Cytop, Nuc \\
\hline & & & 28579255 & & & & & & & & & \\
\hline MeAnn 4 & Manes.11G003900 & Chr11 & $452875-456136$ & 3162 & 1065 & 354 & 9.29 & 40.36 & -0.376 & $43.73 \mathrm{U} 97.32$ & - & Mito, Chlo \\
\hline \multirow[t]{2}{*}{ MeAnn5 } & Manes.11G003800 & Chr11 & $450617-452202$ & 1586 & 954 & 317 & 6.18 & 36.36 & -0.554 & $49.70 \mathrm{U} 88.96$ & - & Cytop, Mito, \\
\hline & & & & & & & & & & & & Nuc \\
\hline \multirow[t]{2}{*}{ MeAnn 6} & Manes.04G165200 & Chr04 & $28574893-$ & 2177 & 1149 & 382 & 5.8 & 43.78 & -0.352 & $50.62 \mathrm{U} 92.43$ & + & Plasm, Nuc \\
\hline & & & 28577069 & & & & & & & & & \\
\hline \multirow[t]{2}{*}{ MeAnn 7} & Manes.04G165100 & Chr04 & $28571325-$ & 2189 & 957 & 318 & 6.67 & 35.89 & -0.271 & $34.21 \mathrm{~S} \quad 100$ & - & Cytop, Nuc \\
\hline & & & 28573513 & & & & & & & & & \\
\hline MeAnn8 & Manes.11G003700 & Chr11 & $445585-448437$ & 2853 & 957 & 318 & 5.94 & 35.88 & -0.333 & $38.25 \mathrm{~S} 96.01$ & - & Cytop, Nuc \\
\hline \multirow[t]{2}{*}{ MeAnn 9} & Manes.15G138400 & Chr15 & $10627745-$ & 2477 & 948 & 315 & 9.46 & 35.79 & -0.444 & $42.65 \mathrm{U} 91.14$ & - & Mito \\
\hline & & & 10630221 & & & & & & & & & \\
\hline \multirow[t]{2}{*}{ MeAnn10 } & Manes.09G138900 & Chr09 & $25831927-$ & 1862 & 1038 & 345 & 8.5 & 38.98 & -0.379 & $45.06 \mathrm{U} 80.14$ & - & Mito, Nuc \\
\hline & & & 25833788 & & & & & & & & & \\
\hline MeAnn11 & Manes.06G001900 & Chr06 & $527782-530910$ & 3129 & 951 & 316 & 9.26 & 35.61 & -0.327 & $34.27 \mathrm{~S} 90.51$ & - & Mito \\
\hline \multirow[t]{2}{*}{ MeAnn 12} & Manes.17G089200 & Chr1 7 & $23235068-$ & 1750 & 930 & 309 & 9.17 & 35.26 & -0.375 & $34.57 \mathrm{~S} 93.46$ & - & Cytop, Mito, \\
\hline & & & 23236817 & & & & & & & & & $\mathrm{Nuc}$ \\
\hline
\end{tabular}

Notes: PL, Protein length; MW, Molecular weight of the amino acid sequence; GRAVY, grand average of hydropathicity; pI, theoretical isoelectric point; II, Instability index; AI, Aliphatic index; S, stable; U, unstable; Cytop, cytoplasm; Mito, mitochondria; Nuc, nucleus; Chlo, chloroplast; and Plasm, plasma membrane. 
Figures

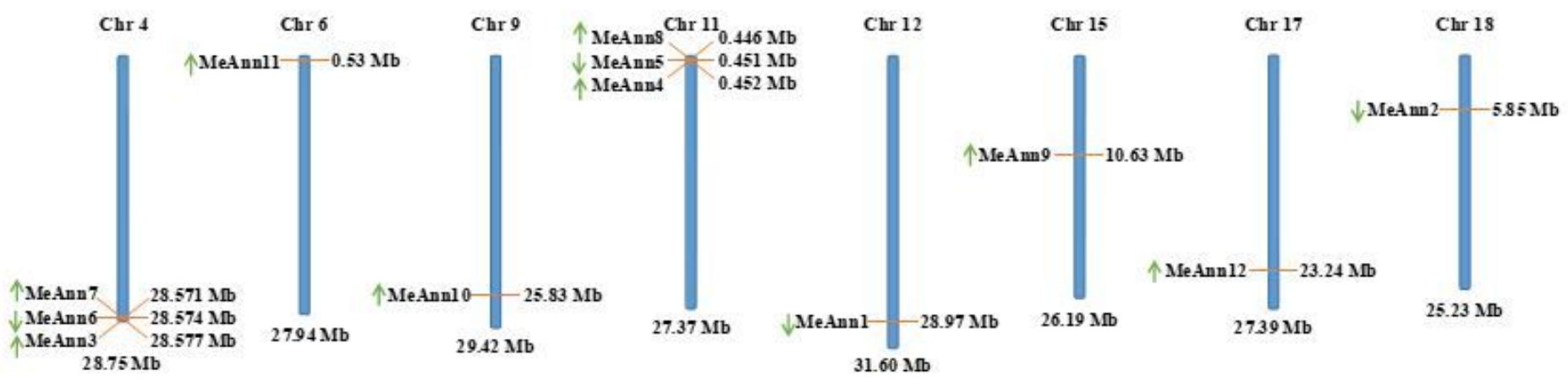

\section{Figure 1}

Location and distribution of the 12 MeAnns on the chromosomes. The chromosome number is labeled at the top of each chromosome. The gene orientation on the chromosomes is indicated by green arrows. The chromosome size is labeled at the bottom of each chromosome. The position of gene on the chromosome is labeled to the right of each gene. 


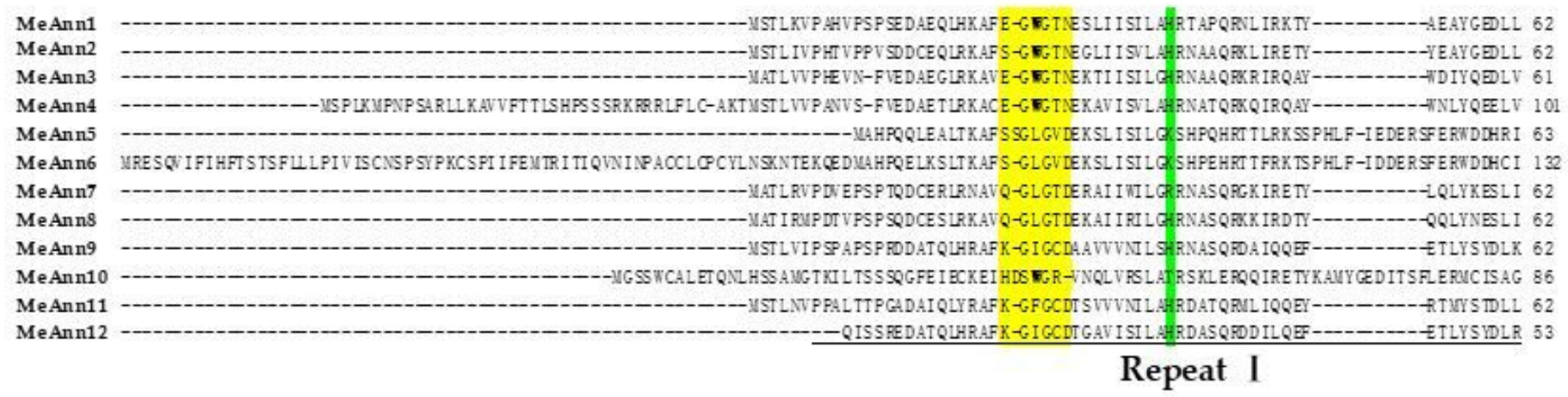

MeAnn1 KALDYELSSDFERSLUTTLDPAERDAYLANEATMRF--TSSNVLÜE IACTRSSLELFWVRQAYHARYKRSI EEDV AYHTTGD-FRKLLVPLVSSFYYGEEVMSLAKSEAKILHEKISD---KATSDDE 188

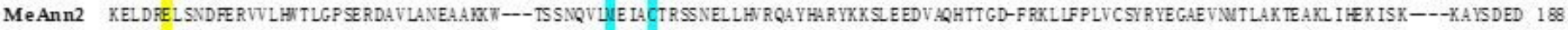
MeAnn3 KRLESE I SGDFERAVY RV ILDPERRDAVLANVALW----GSDHHV IVE IACVRSSEELLAVRRAYHARYKRSLEEDVAAHTTDD-VRKLLVGLVTAFRYEGTE IDVKLAKCEAKIL@A IKD---KKRRHDE 186

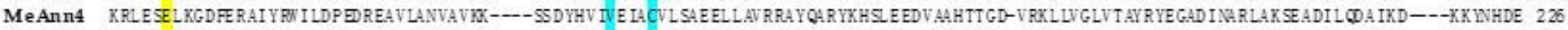

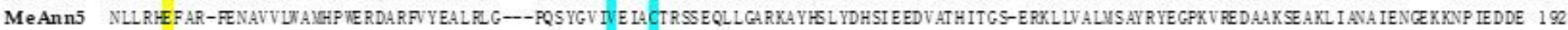
MeAnn6 TLLRHEFL-FENAVVITAMHP TERDARSVYEALRLG---SYDVIV E IACTRSSEELLGARKAYHSL YDHSI EEDVATHITSS-ERKLLVALVSAYRYEGPKVPED IAKFEAKL I AVA IKNCDEKNP IEDDE 239

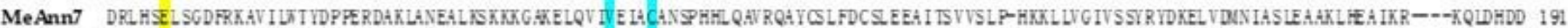

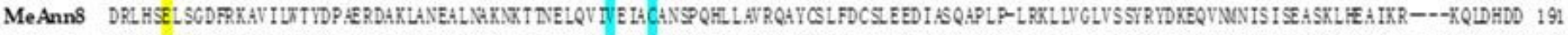

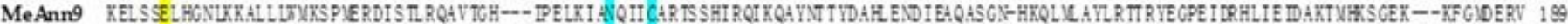

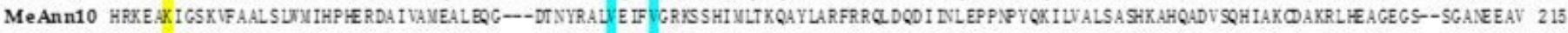

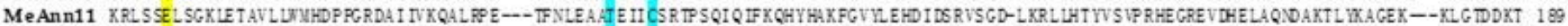

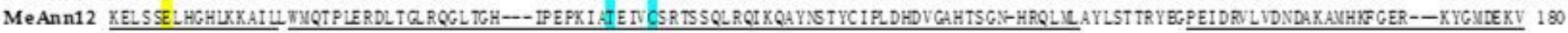

\section{Repeat II}

\section{Repeat III}

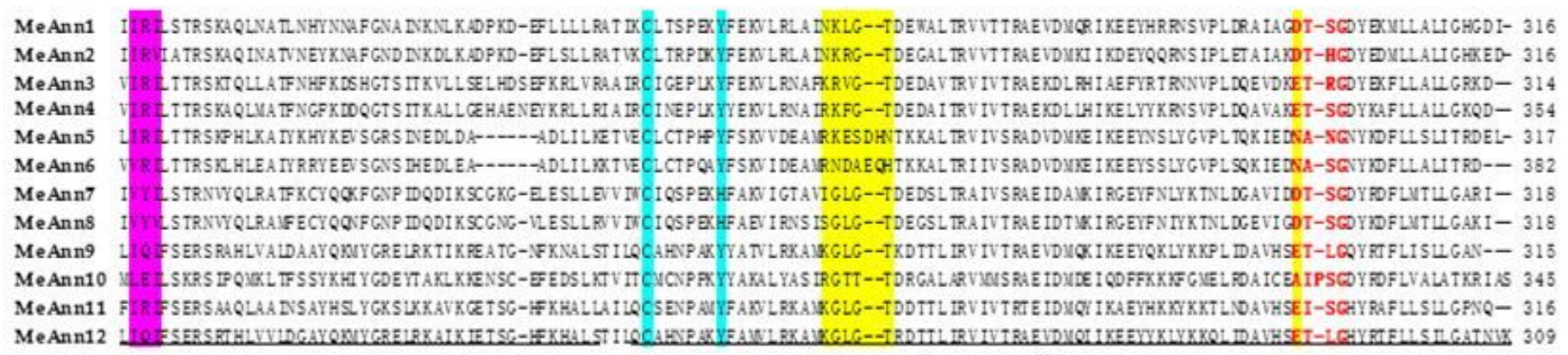

Repeat IV

Figure 2

Multiple sequence alignment of the cassava MeAnns. The putative MeAnn repeats $\mathbb{\nabla} \nabla$ are underlined; shaded yellow sequences denote the type $\triangle$ calcium binding sites; shaded green sequences are the conserved heme-binding sites; shaded purple red sequences represent the actin binding sites; shaded light blue sequences are the putative S3 clusters related to redox reactions; red bold amino acids within Repeat IV are the putative GTP-binding motifs; and black bold amino acids within Repeat I indicate the putative phospholipid-binding sites. 




Figure 3

Phylogenetic relationships among MeAnns and other plant annexins. The prefixes At, Os, Solyc and MeAnn indicate proteins from $\mathrm{O}$. sativa, S. lycopersicum, A. thaliana and M. esculenta, respectively. 
(A)

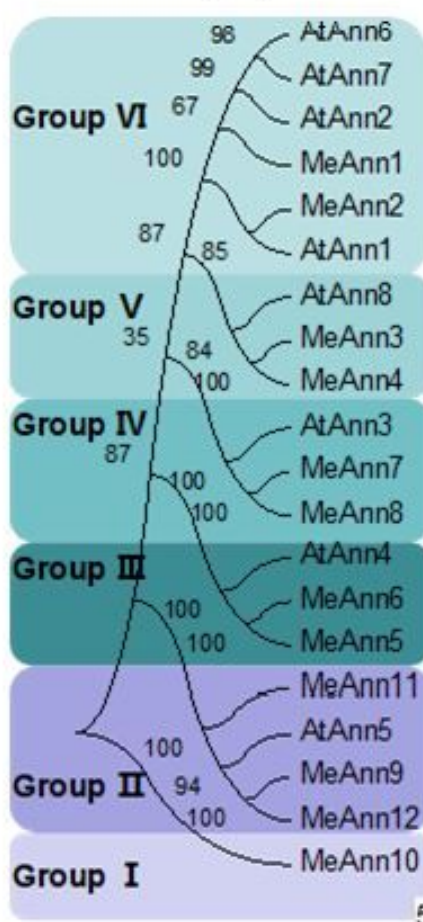

(B)

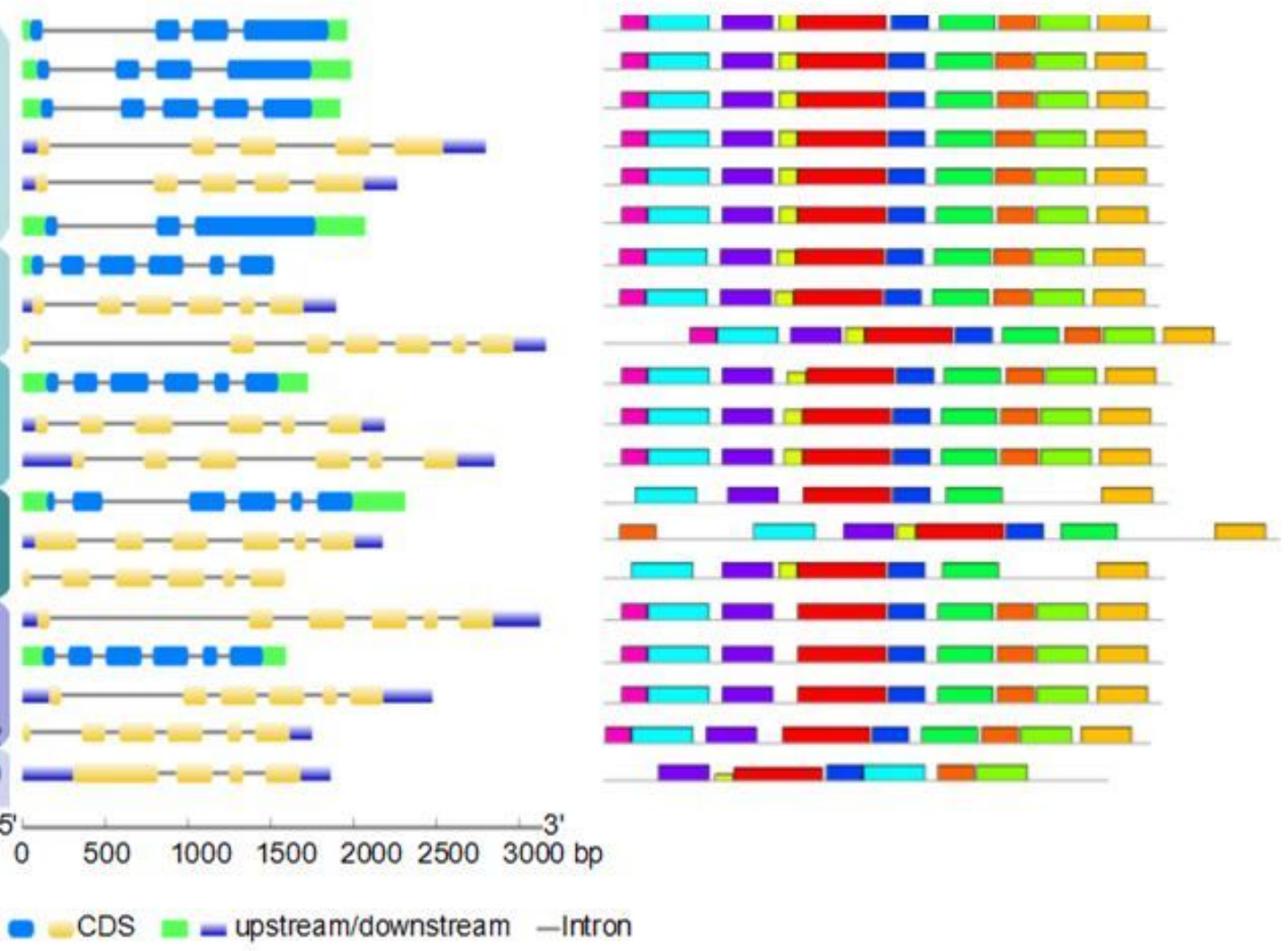

$\square$ motif $1 \square$ motif $2 \square$ motif $3 \square$ motif $4 \square$ motif $5 \square$ motif $6 \square$ motif $7 \square$ motif $8 \square$ motif $9 \square$ motif 10

\section{Figure 4}

Comparative analyses of the phylogenetics, structures, and motifs of MeAnns and AtAnns. (A) The phylogenetic relationship of MeAnns and AtAnns. (B) The gene structures of MeAnns and AtAnns. (C) The motifs in the MeAnn and AtAnn proteins. The genes in Figures A, B and C are ordered in the same. 


\begin{tabular}{|c|c|c|c|c|c|c|c|c|c|c|c|c|c|c|c|c|c|c|c|c|c|c|c|c|c|c|}
\hline Type & \multicolumn{12}{|c|}{ Hormone-relative elements } & \multicolumn{14}{|c|}{ Stress-relative elements } \\
\hline cis-element & $\begin{array}{l}\frac{1}{2} \\
\frac{0}{2} \\
\frac{m}{\alpha}\end{array}$ & 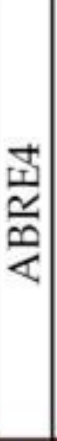 & $\vec{d}$ & 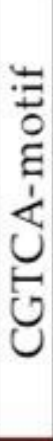 & 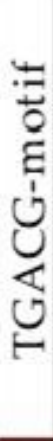 & $\mid \begin{array}{c}\mid \\
\frac{1}{1} \\
\frac{1}{y} \\
\end{array}$ & 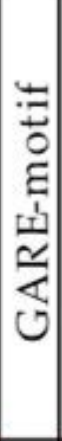 & 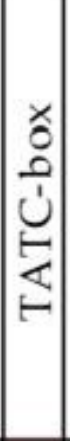 & $\underset{\forall}{\mho}$ & 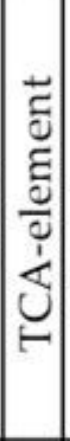 & $\begin{array}{l}x \\
0 \\
0 \\
\dot{\Sigma} \\
\vdots \\
ن\end{array}$ & 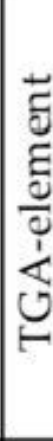 & $\frac{1}{2}$ & 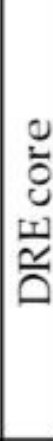 & $\stackrel{\simeq}{\exists}$ & $\stackrel{\sim}{\stackrel{n}{\Sigma}}$ & $\frac{2}{3}$ & 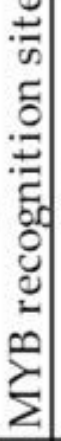 & $\sum_{\Sigma}^{\infty}$ & $\frac{\vec{z}}{2}$ & $\underbrace{\cup}_{\Sigma}$ & 可 & 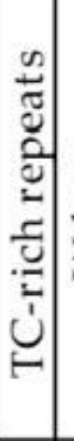 & 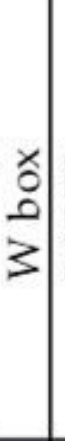 & $\begin{array}{l}2 \\
\frac{3}{3} \\
\frac{3}{3} \\
3\end{array}$ & है \\
\hline MeAnn1 & 4 & 1 & 3 & 3 & 3 & 6 & & 1 & & & & & 1 & & 1 & & 3 & & & 2 & 2 & & & 1 & & 2 \\
\hline MeAnn2 & 2 & 2 & & & & 7 & & & & & & & 1 & & & & & & 4 & 1 & & & 1 & 1 & 1 & 1 \\
\hline MeAnn3 & 2 & & & & & 7 & & & & 1 & & & 1 & & & 1 & 1 & & & & & & 1 & & & 1 \\
\hline MeAnn4 & 1 & & 1 & 1 & 1 & 6 & 1 & 1 & & & & 1 & 2 & & & & 2 & & 6 & & 4 & 1 & & & & 2 \\
\hline MeAnn5 & 2 & & & & & 1 & & & & 1 & & 1 & 2 & 1 & & 1 & 2 & 2 & 1 & 1 & 3 & 1 & & & & 2 \\
\hline MeAnn6 & 3 & 1 & & & & 2 & 2 & & 1 & 1 & & & 1 & & & & & & 3 & & 4 & \begin{tabular}{|l|}
2 \\
\end{tabular} & & & 1 & 1 \\
\hline MeAnn7 & 3 & 1 & & & & 2 & 2 & & 1 & 1 & & & 1 & & & & & & 4 & & 4 & 1 & & & 1 & 1 \\
\hline MeAnn8 & \begin{tabular}{|l|}
2 \\
\end{tabular} & & & & & 1 & & & & 2 & & 1 & 3 & 1 & 1 & 1 & 2 & 2 & 1 & 1 & 3 & 2 & & 1 & & 3 \\
\hline MeAnn9 & & & 2 & 2 & 2 & 5 & & & 1 & 2 & 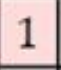 & & & 1 & 3 & & & & 6 & & 2 & 4 & & & & \\
\hline MeAnn 10 & & & & & & 6 & & 1 & & 1 & & & & & & & 2 & & 4 & & 7 & 2 & & & & 5 \\
\hline MeAnn11 & 1 & 1 & & & & 1 & 1 & 2 & & 1 & & 1 & 1 & & 2 & 3 & 5 & & 2 & 2 & 3 & & & 1 & 2 & \\
\hline MeAnn12 & & & & & & 6 & & 2 & & & & & & & & 2 & 3 & & & & 1 & 1 & 2 & 1 & & \\
\hline
\end{tabular}

Figure 5

The stress- and hormone-related cis-acting elements in the cassava MeAnn gene promoters. 


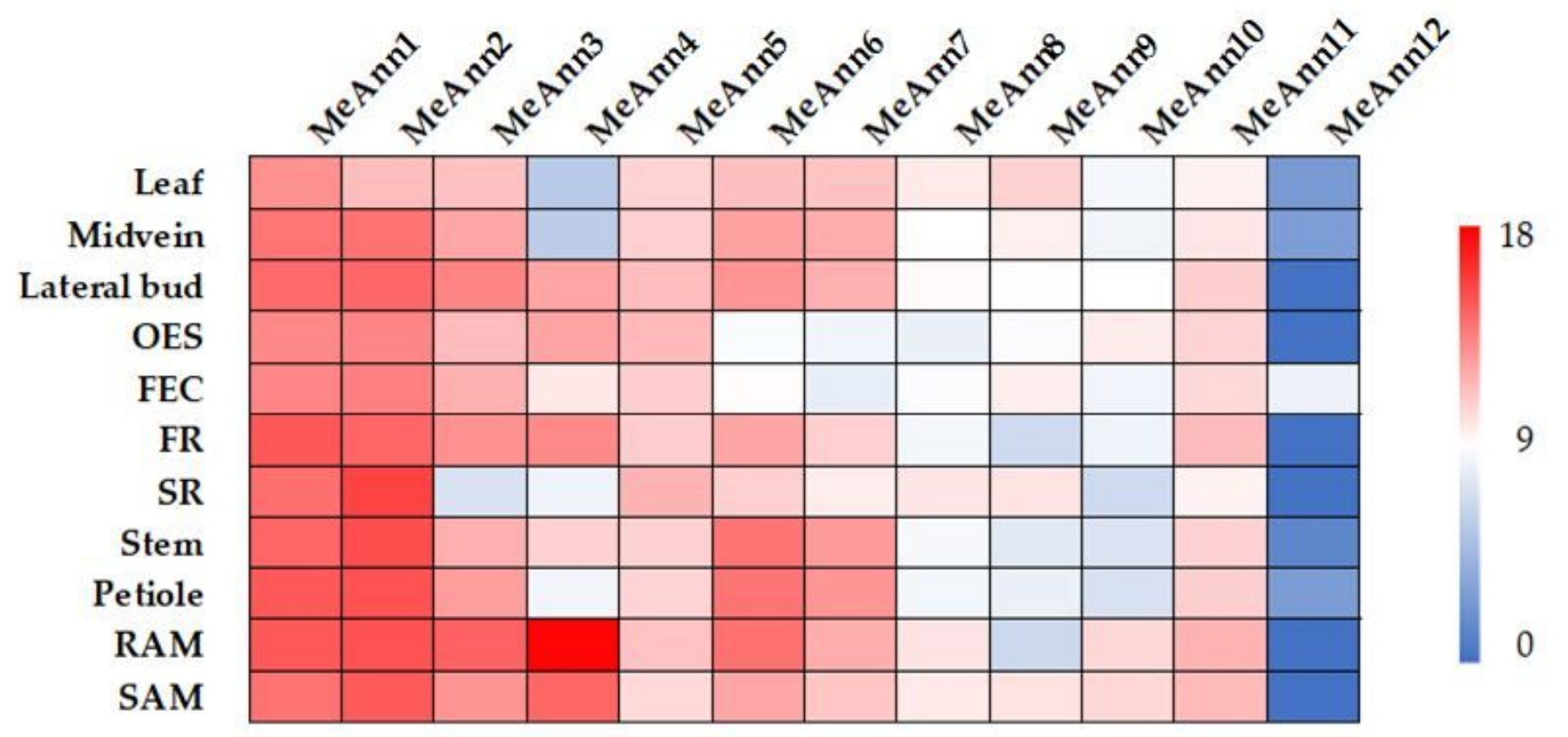

\section{Figure 6}

Gene expression levels of MeAnns in multiple cassava organs or tissues. OES, the somatic organized embryogenics; FEC, the friable embryogenic calli; FR, the fibrous roots; SR, storage roots; RAM, the root apical meristems; and SAM, shoot apical meristems. The gradient bar on the right indicates the Log2corrected FPKM values (fragments per kilobase of exons per million reads mapped). 


\begin{tabular}{|c|c|c|c|c|c|c|c|c|c|c|c|c|c|}
\hline $4^{\circ} \mathrm{C}-3 \mathrm{~h} / \mathrm{CK} \mathrm{L}$ & $*$ & $*$ & & $*$ & $*$ & $*$ & & & $*$ & $*$ & & & \\
\hline $4^{\circ} \mathrm{C}-6 \mathrm{~h} / \mathrm{CK} \mathrm{L}$ & $*$ & $*$ & & $*$ & * & $*$ & & & $*$ & $*$ & & & 10 \\
\hline $4^{\circ} \mathrm{C}-9 \mathrm{~h} / \mathrm{CK} \mathrm{L}$ & $*$ & & $*$ & & * & $*$ & * & & * & $*$ & * & $*$ & \\
\hline $4^{\circ} \mathrm{C}-12 \mathrm{~h} / \mathrm{CK} \mathrm{L}$ & $*$ & $*$ & $*$ & & $*$ & $*$ & $*$ & & $*$ & $*$ & & $*$ & \\
\hline $4^{\circ} \mathrm{C}-24 \mathrm{~h} / \mathrm{CK} \mathrm{L}$ & $*$ & $*$ & & * & $*$ & $*$ & & & $*$ & $*$ & & & \\
\hline $4^{\circ} \mathrm{C}-48 \mathrm{~h} / \mathrm{CK} \mathrm{L}$ & $*$ & $*$ & * & & * & $*$ & & & $*$ & $*$ & & & \\
\hline $4^{\circ} \mathrm{C}-3 \mathrm{~h} / \mathrm{CKS}$ & & & & * & & & & & & $*$ & * & & \\
\hline $4^{\circ} \mathrm{C}-6 \mathrm{~h} / \mathrm{CK} \mathrm{S}$ & & & & $*$ & & & & & $*$ & & & $*$ & 0 \\
\hline $4^{\circ} \mathrm{C}-9 \mathrm{~h} / \mathrm{CK} \mathrm{S}$ & * & $*$ & & & * & $*$ & & & $*$ & $*$ & & & \\
\hline $4^{\circ} \mathrm{C}-12 \mathrm{~h} / \mathrm{CKS}$ & $*$ & $*$ & & & & & & * & $*$ & $*$ & * & & \\
\hline $4^{\circ} \mathrm{C}-24 \mathrm{~h} / \mathrm{CKS}$ & & & & & & & $*$ & & & $*$ & & * & \\
\hline $4^{\circ} \mathrm{C}-48 \mathrm{~h} / \mathrm{CKS}$ & & & & * & & & * & & $*$ & $*$ & & $*$ & \\
\hline $4^{\circ} \mathrm{C}-3 \mathrm{~h} / \mathrm{CK} \mathrm{R}$ & $*$ & & & & & & & & $*$ & $*$ & & * & \\
\hline $4^{\circ} \mathrm{C}-6 \mathrm{~h} / \mathrm{CK} \mathrm{R}$ & $*$ & & & & & & & & $*$ & $*$ & & $*$ & -8 \\
\hline $4^{\circ} \mathrm{C}-9 \mathrm{~h} / \mathrm{CK} \mathrm{R}$ & $*$ & & & $*$ & & & & & $*$ & $*$ & & * & \\
\hline $4^{\circ} \mathrm{C}-12 \mathrm{~h} / \mathrm{CK} \mathrm{R}$ & $*$ & $*$ & & * & & & * & & * & & & * & \\
\hline $4^{\circ} \mathrm{C}-24 \mathrm{~h} / \mathrm{CK} \mathrm{R}$ & $*$ & & & * & & & & & $*$ & $*$ & $*$ & * & \\
\hline $4^{\circ} \mathrm{C}-48 \mathrm{~h} / \mathrm{CK} \mathrm{R}$ & $*$ & & & $*$ & & & * & & $*$ & & & $*$ & \\
\hline
\end{tabular}

\section{Figure 7}

Expression patterns of MeAnns in leaves, shoots and roots under $4^{\circ} \mathrm{C}$ cold stress. The gradient bar on the right indicates the Log2-normalized relative gene expression levels. L, leaves; $S$, shoots; and $R$, roots. The stars indicate values greater than 2 -fold. 


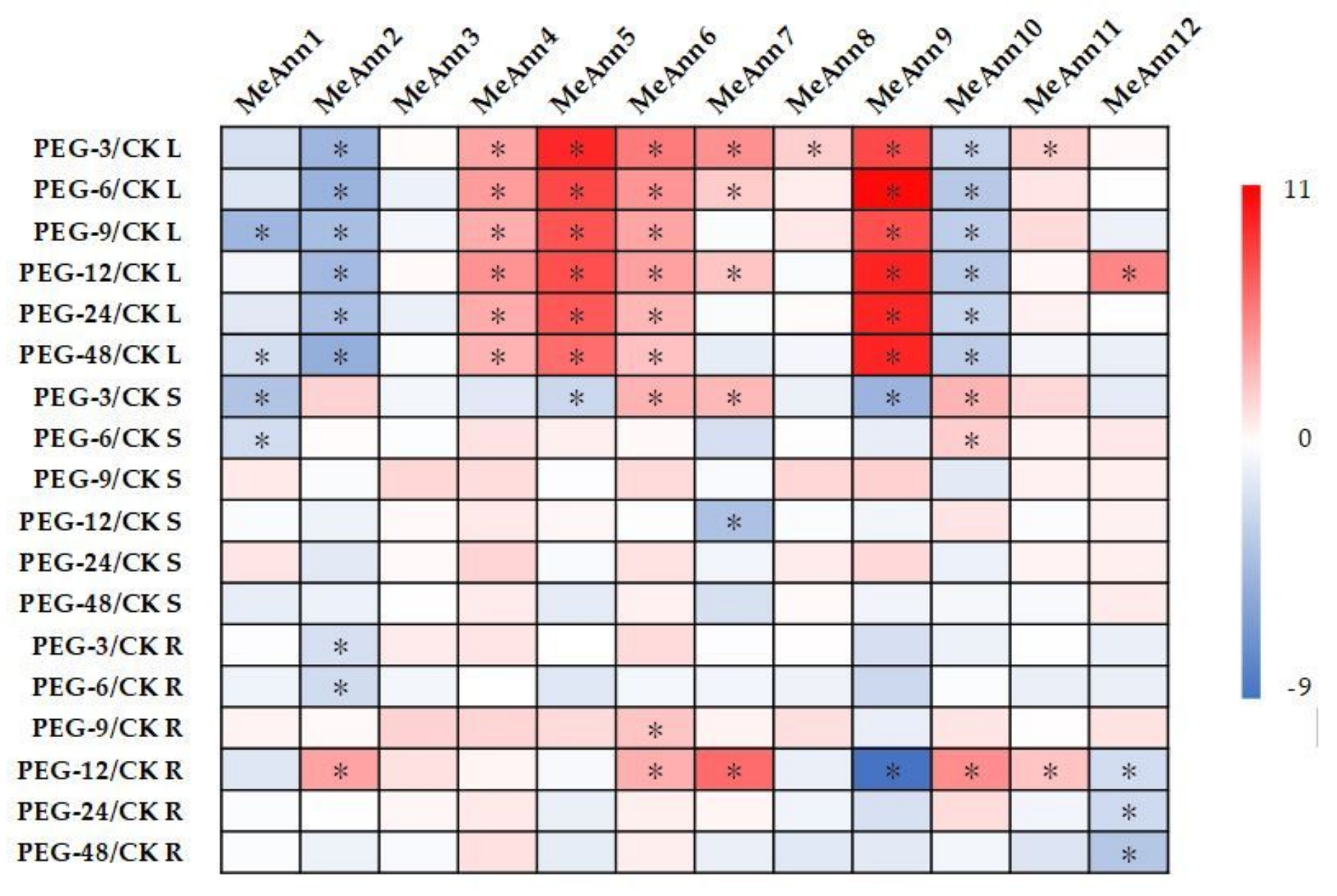

Figure 8

Expression patterns of MeAnns in leaves, shoots and roots under 20\% PEG6000-induced drought stress. The gradient bar on the right indicates the Log2-normalized relative gene expression levels. L, leaves; $\mathrm{S}$, shoots; and R, roost. The stars indicate values greater than 2 -fold. 
NaCl-3 h/CK L

NaCl-6 h/CK L

NaCl-9 h/CK L

NaCl-12 h/CK L

NaCl-24 h/CK L

NaCl-48 h/CK L

NaCl-3 h/CK S

NaCl-6 h/CK S

NaCl-9 h/CK S

NaCl-12 h/CK S

NaCl-24 h/CK S

NaCl-48 h/CK S

NaCl-3 h/CK R

NaCl-6 h/CK R

NaCl-9 h/CK R

NaCl-12 h/CK R

NaCl-24 h/CK R

NaCl-48 h/CK R

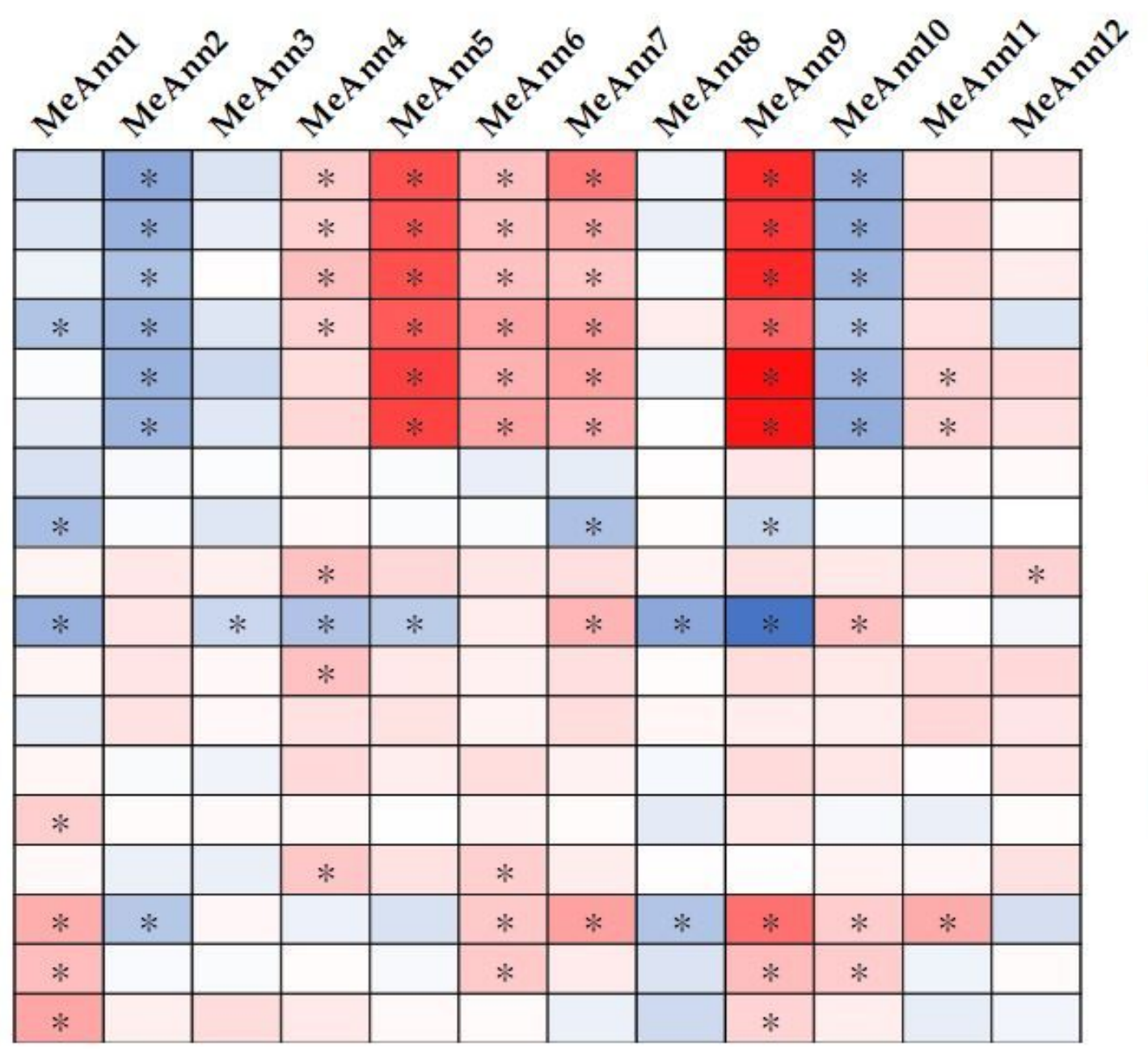

Figure 9

Expression patterns of MeAnns in leaves, shoots and roots under $300 \mathrm{mmol} / \mathrm{L} \mathrm{NaCl}$-induced salt stress. The gradient bar on the right indicates the Log2-normalized relative gene expression levels. L, leaves; $\mathrm{S}$, shoots; and R, roost. The stars indicate values greater than 2 -fold. 
$\mathrm{CaCl2}-10 / \mathrm{CK} \mathrm{L}$

$\mathrm{CaCl2}-20 / \mathrm{CK} \mathrm{L}$

$\mathrm{CaCl} 2-30 / \mathrm{CK} \mathrm{L}$

CaC12-40/CK L

$\mathrm{CaCl} 2-50 / \mathrm{CK} \mathrm{L}$

CaCl2-10/CK S

CaCl2-20/CK S

$\mathrm{CaCl}-30 / \mathrm{CK} S$

CaC12-40/CK S

$\mathrm{CaCl2}-50 / \mathrm{CK} S$

$\mathrm{CaC12}-10 / \mathrm{CK} \mathrm{R}$

CaCl2-20/CK R

$\mathrm{CaCl2}-30 / \mathrm{CK} \mathrm{R}$

CaC12-40/CK R

CaCl2-50/CK R

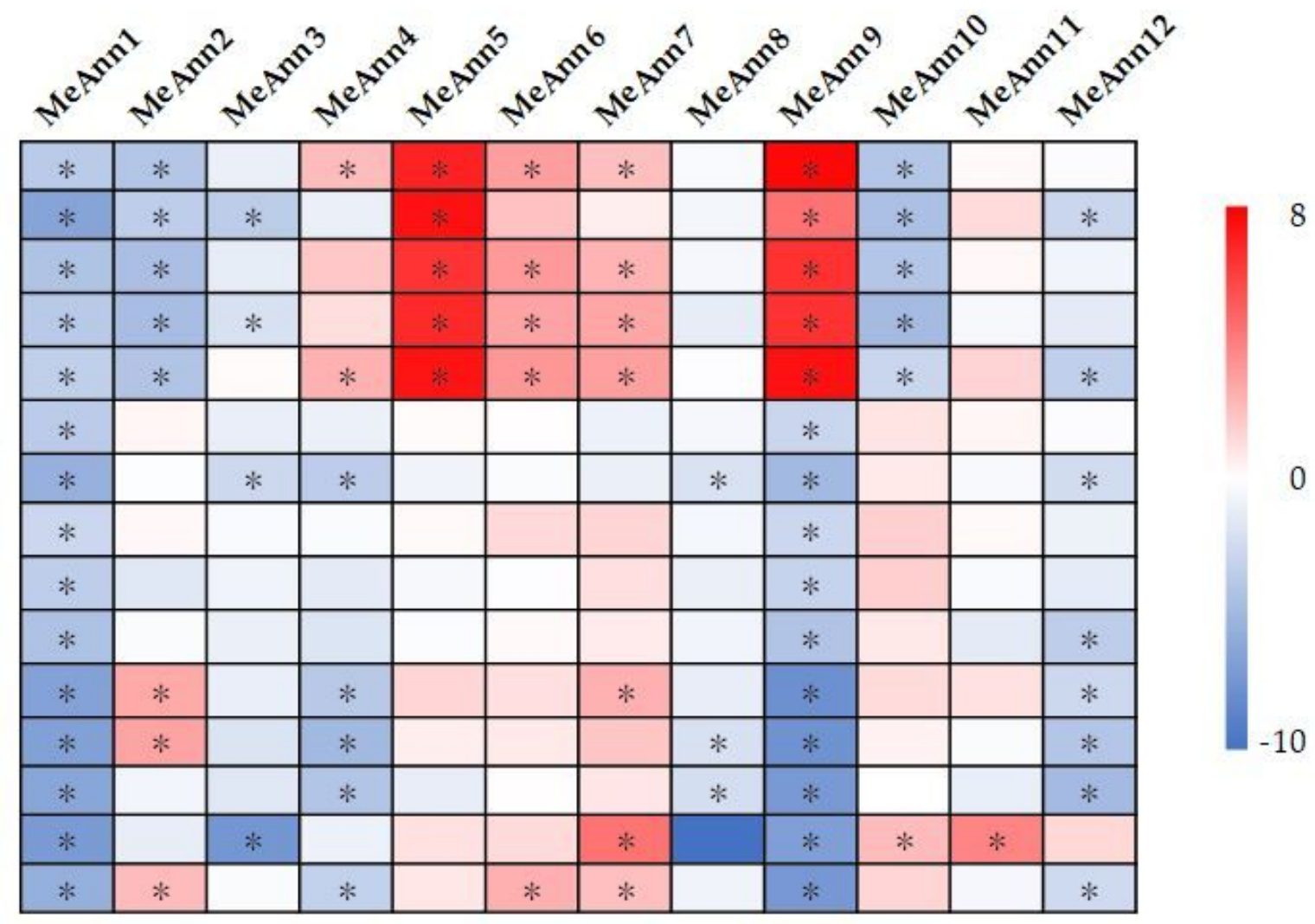

Figure 10

Expression patterns of MeAnns in leaves, shoots, and roots under $\mathrm{CaCl} 2$-induced $\mathrm{Ca} 2+$ signaling. The gradient bar on the right indicates the Log2-normalized relative gene expression levels. L, leaves; $S$, shoots; and $\mathrm{R}$, roost. The stars indicate values greater than 2 -fold. 


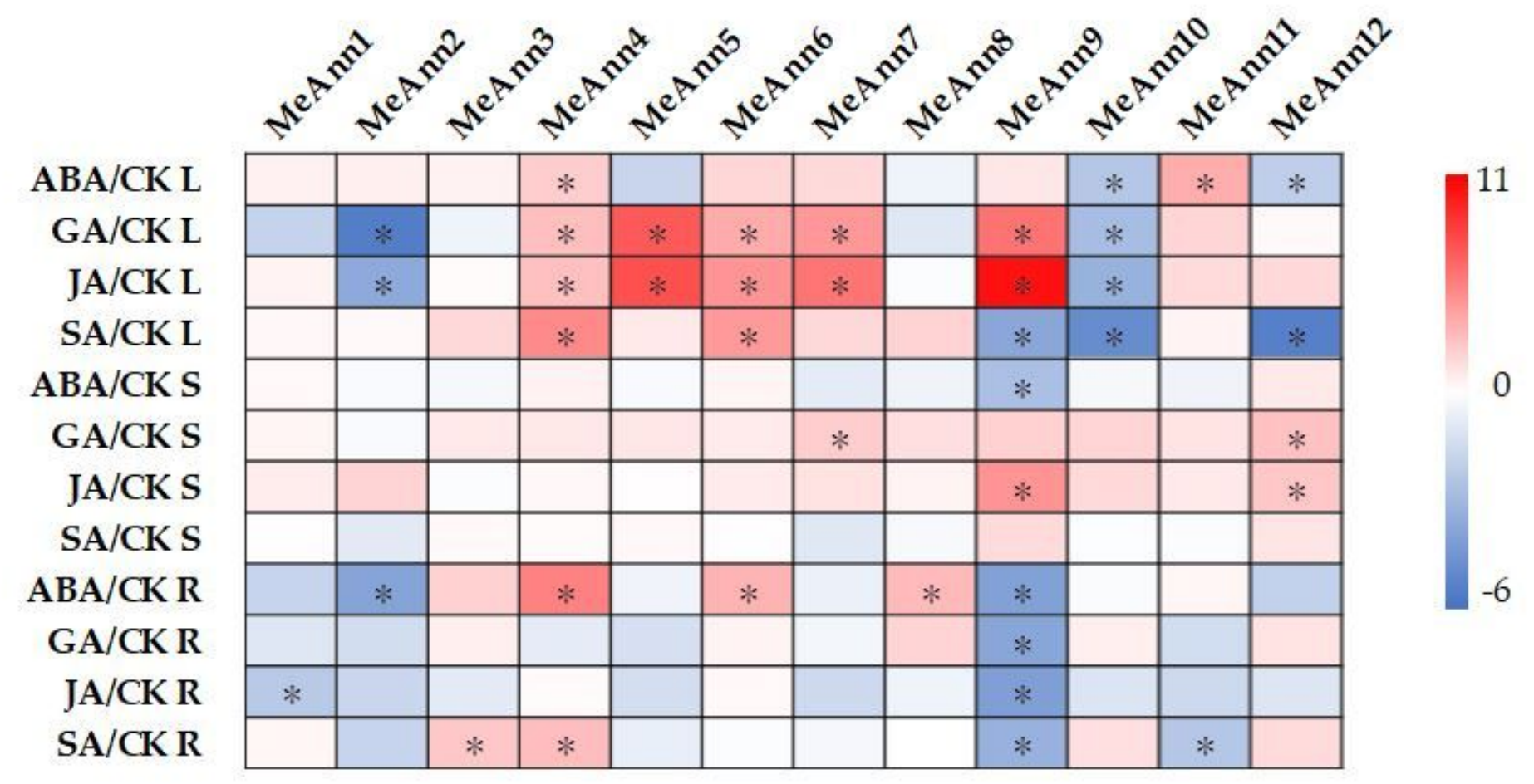

Figure 11

Expression patterns of MeAnns in leaves, shoots, and roots under different hormone treatments. The gradient bar on the right indicates the Log2-normalized relative gene expression levels. L, leaves; $S$, shoots; and R, roost. The stars indicate values greater than 2 -fold.

\section{Supplementary Files}

This is a list of supplementary files associated with this preprint. Click to download.

- TableS.xls 